\title{
Characteristics of Background Error Covariance of Soil Moisture and Atmospheric States in Strongly Coupled Land-Atmosphere Data Assimilation
}

\author{
LIAO-FAN LIN AND ZHAOXIA PU \\ Department of Atmospheric Sciences, University of Utah, Salt Lake City, Utah
}

(Manuscript received 20 February 2018, in final form 31 July 2018)

\begin{abstract}
This study characterizes the spatial and temporal variability of the background error covariance between the land surface soil moisture and atmospheric states for a better understanding of the potentials of assimilating satellite soil moisture data under a framework of strongly coupled land-atmosphere data assimilation. The study uses the Noah land surface model coupled with the Weather Research and Forecasting (WRF) Model and the National Meteorological Center (NMC) method for computing the land-atmosphere background error covariance from 2015 to 2017 over the contiguous United States. The results show that the forecast errors in top-10-cm soil moisture and near-surface air potential temperature and specific humidity are correlated and relatively large during the daytime in the summer. The magnitude of the error correlation between these three states is comparable. For example, in July, the error correlation averaged over all dayand nighttime samples is -0.13 for near-surface temperature and humidity, -0.20 for surface soil moisture and near-surface temperature, and 0.15 for surface soil moisture and near-surface humidity. During the summer, the forecast errors in surface soil moisture are correlated with those of atmospheric states up to the sigma pressure level of 0.9 (approximately $900 \mathrm{hPa}$ for a sea level location) with domain-mean correlations of -0.15 and 0.1 for temperature and humidity, respectively. The results suggest that assimilation of satellite soil moisture data could provide cross-variable impacts comparable to those assimilating conventional nearsurface temperature and humidity data. The forecast errors of soil moisture are only marginally correlated with those of the winds.
\end{abstract}

\section{Introduction}

A modern numerical weather prediction (NWP) model often includes a land surface model to provide an estimation of sensible and latent heat fluxes directly to its bottom atmospheric layer. For a land surface model, the state of soil moisture is particularly important. Research has shown that weather and precipitation predictions are sensitive to the soil moisture conditions (Sutton et al. 2006; Aligo et al. 2007; Trier et al. 2008; Hohenegger et al. 2009; Van Weverberg et al. 2010; Quintanar and Mahmood 2012). More accurate soil moisture estimation was shown to be useful for improving the diurnal variability of the near-surface temperature, humidity, and wind forecasts (Case et al. 2008, 2011; Massey et al. 2016).

Since the late 1990s, several NWP centers have implemented an optimal interpolation (OI) method proposed by Mahfouf (1991) to improve soil moisture analyses.

\footnotetext{
Corresponding author: Liao-Fan Lin, liaofan.lin@utah.edu
}

In this method, soil moisture analyses are updated according to 1) the increments between the forecasts and observations of temperature and relative humidity at 2-m height (2-m temperature and humidity) and 2) an empirical background error covariance between 2-m temperature and humidity and soil moisture (Mahfouf 1991). Via the error covariance, the soil moisture storage would typically have a positive analysis increment (analysis minus background) when there is an overestimation of temperature or underestimation of humidity in the forecasts. Given the lack of soil moisture measurements to be assimilated from the late 1990s to early 2000s, it has been demonstrated that this OI method is helpful, and it has been adopted by the European Centre for MediumRange Weather Forecasts (ECMWF) (Douville et al. 2000). According to the review in De Rosnay et al. (2014), this OI method has also been implemented in ECMWF reanalyses (Uppala et al. 2005; Dee et al. 2011), the global and regional weather model at Météo-France (Giard and Bazile 2000), and the Canadian regional weather forecast model (Bélair et al. 2003). 
During the past decade, direct assimilation of satellite soil moisture retrievals has been investigated extensively, particularly after 2009 due to the operation of two L-band satellites in the Soil Moisture and Ocean Salinity (SMOS; Kerr et al. 2010) and Soil Moisture Active Passive (SMAP; Entekhabi et al. 2010) missions. With these satellite sensors and their retrievals, L-band microwave radiometers can detect deeper $(\sim 5 \mathrm{~cm})$ soil information over bare soil and vegetation of up to $5 \mathrm{~kg} \mathrm{~m}^{-2}$ water content, while $\mathrm{C}$ - and $\mathrm{X}$-band radiometers [e.g., the Advanced Microwave Scanning Radiometer for EOS (AMSR-E) and Tropical Rainfall Measuring Mission (TRMM) Microwave Imager] can measure only the top-1-cm soil moisture over vegetation of less water content (Entekhabi et al. 2010). To assimilate soil moisture retrievals, most studies have used ensemblebased methods such as the ensemble Kalman filter and have tested with offline land surface models. Examples of these models include the NASA Land Information System (LIS; Kumar et al. 2008, 2014, 2015; Sahoo et al. 2013; Yin et al. 2014, 2015; Blankenship et al. 2016), the NASA Catchment land surface model (Reichle and Koster 2005; Reichle et al. 2007, 2008; Draper et al. 2012; Kolassa et al. 2017), and the Canadian Modelisation Environmentale-Surface et Hydrologie model (MESH; Xu et al. 2015, 2017). This type of application often uses model forcing of precipitation and radiation from measurements or reanalyses and does not interact with or have any feedback to an atmospheric model. Therefore, discussion about the impact of assimilating soil moisture data is constrained mainly by variables such as soil temperature and moisture in a land surface model.

A coupled data assimilation system is needed to study the impact of soil moisture assimilation on NWP. There are two types of coupling: weakly and strongly coupled data assimilation (Penny and Hamill 2017; Penny et al. 2017). With weakly coupled data assimilation, assimilating observations into a model does not affect the control states of the other coupled model(s) during the analysis process. The impact of a weakly coupled data assimilation system on the entire domain is seen only via model integration. On the contrary, strongly coupled data assimilation requires the estimation of error covariance of the control states in all the coupled models and the simultaneous computation of the analysis across the entire domain. Mahfouf et al. (2009) proposed a modeling framework that is flexible in assimilating land surface observations such as soil moisture and 2-m temperature and humidity based on an extended Kalman filter. This approach has been tested and is operational in a land surface model coupled to Météo-France's Aire Limitée Adaptation
Dynamique Développement International (ALADIN) limited area model (Draper et al. 2009, 2011; Mahfouf 2010; Mahfouf and Bliznak 2011; Parrens et al. 2014; Schneider et al. 2014; Duerinckx et al. 2017) and the Integrated Forecast System at ECMWF (Drusch et al. 2009; De Rosnay et al. 2013). In addition, several studies have developed a coupled data assimilation system with the Weather Research and Forecasting (WRF) Model to assimilate soil moisture information (Rasmy et al. 2011, 2012; Santanello et al. 2016; Seto et al. 2016; Lin et al. 2017a). Nonetheless, none of these studies addresses the problems in strongly coupled data assimilation. The soil moisture analyses can be directly affected via the assimilation of near-surface temperature and humidity observations by using the previously mentioned OI method (Mahfouf 1991). Therefore, in a strongly coupled system, one could expect that assimilating soil moisture data directly impacts atmospheric control states and forecasts. However, to what extent can the soil moisture variable be associated with various atmospheric control states spatially within the context of data assimilation regarding the error covariance? To answer this question, a deep understanding of the error covariance between soil moisture and atmospheric states within a strongly coupled land-atmosphere model is not only the first step but also a must.

In light of these issues, this study characterizes the space-time variability of the error covariance of surface soil moisture and atmospheric states in a coupled land-atmosphere model. To our best knowledge, this type of investigation has not yet been done. Specifically, instead of only specifying the error characteristics for either soil moisture state (Lin et al. 2017b) or atmospheric state variables, we adopt the National Meteorological Center (NMC) method (Parrish and Derber 1992) to obtain background error statistics from multiple numerical experiments using the WRF Model with the Noah land surface model and to generate the covariance across both the atmosphere and land surface models. The NMC method has been adopted by the National Centers for Environmental Prediction (NCEP; Parrish and Derber 1992; Wu et al. 2002), the Met Office (Lorenc et al. 2000; Ingleby 2001), and the WRF data assimilation community (e.g., Li et al. 2014; Wang et al. 2014; Lin et al. 2015; Sun et al. 2016; Yang et al. 2016; Choi et al. 2017). Several ensemble Kalman filter-based atmospheric data assimilation systems have also used NMC-based climatological error covariance statistics to perturb the model initial conditions (e.g., Zhang et al. 2006; Meng and Zhang 2007, 2008; Wu et al. 2010). To examine the potential influence of soil moisture data assimilation on atmospheric states, we estimate the 
background error covariance of the top-10-cm soil moisture and several key atmospheric variables, including potential temperature, specific humidity, and zonal and meridional winds. To emphasize shortrange weather forecasting, we compute the background error by using 12- and 24-h forecasts valid at the same time. Considering the monthly and seasonal variability of soil moisture and atmospheric states, the calculations are conducted for each month from 2015 to 2017.

The rest of the paper is organized as follows. Section 2 explains the formulations, the scope of the study, and the experiment design. In section 3, we characterize the spatial and temporal variability of the background error covariance between the land surface soil moisture and atmospheric states. Section 4 includes the conclusions and future perspectives.

\section{Methodology}

\section{a. Configuration of the domain and the WRF-Noah Model}

This study uses WRF version 3.9.1 (Skamarock et al. 2008; Powers et al. 2017) with the Advanced Research version of WRF (ARW) solver. The WRF Model is a regional climate and weather model for both research and operations and is currently maintained by the National Center for Atmospheric Research (NCAR). We employ the WRF's CONUS physics suite, which is a group of well-tested physics schemes that often produces good results (see the WRF User Guide at http://www2.mmm.ucar.edu/wrf/users/docs/user_guide_ V3.9/contents.html). This suite includes the new Thompson microphysics scheme (Thompson et al. 2008), the Rapid Radiative Transfer Model (RRTM) longwave and shortwave schemes (Iacono et al. 2008), the MoninObukhov-based Eta similarity surface-layer scheme (Janjić 2002), the Noah land surface model (Chen and Dudhia 2001), the Mellor-Yamada-Janjić planetary boundary layer scheme (Janjić 1994), and the Tiedtke cumulus parameterization scheme (Tiedtke 1989; Zhang et al. 2011).

A single domain of the Lambert conformal projection is configured with grid spacing of $9 \mathrm{~km}$ and $602 \times$ 392 grids horizontally. The top pressure level is at $5000 \mathrm{~Pa}$ with 40 atmospheric layers below. The corresponding sigma levels from the surface to the top pressure level are 1, 0.99, 0.98, 0.97, 0.95, 0.93, 0.90, 0.88, 0.85, and 0.82 (levels 1-10); 0.78, 0.75, 0.69, 0.64, 0.59, 0.54, $0.49,0.45,0.41$, and 0.37 (levels 11-20); 0.34, 0.30, 0.27, $0.25,0.22,0.19,0.17,0.15,0.13$, and 0.11 (levels 21-30); and $0.10,0.08,0.07,0.06,0.05,0.04,0.03,0.02,0.01,0.006$, and 0 (levels 31 and higher). The Noah land surface model has four soil layers as the default, with thicknesses of $10,30,60$, and $100 \mathrm{~cm}$ from top to bottom. Lookup tables are used for the prescribed parameters of land use (vegetation) and soil types. This study domain covers the entire contiguous United States, and the corresponding soil and MODIS-based land-use categories are shown in Fig. 1.

\section{b. Formulation of variational data assimilation and background error covariance estimation}

A classic one- and three-dimensional variational data assimilation (1D- and 3D-Var) system computes optimal states by minimizing the following cost function $J$ in an incremental form (Ide et al. 1997; Courtier et al. 1998):

$$
J(\delta \mathbf{x})=\frac{1}{2} \delta \mathbf{x}^{\mathrm{T}} \mathbf{B}^{-1} \delta \mathbf{x}+\frac{1}{2}(\mathbf{H} \delta \mathbf{x}-\mathbf{d})^{\mathrm{T}} \mathbf{R}^{-1}(\mathbf{H} \delta \mathbf{x}-\mathbf{d}),
$$

where $\delta \mathbf{x}$ is a vector of analysis increment, with $\delta \mathbf{x}^{a}=\mathbf{x}^{a}-\mathbf{x}^{b}$ at the minimum of the cost function, in which $\mathbf{x}^{b}$ and $\mathbf{x}^{a}$ denote the vectors of the background and analysis, respectively; $\mathbf{H}$ denotes the linear form of an operator that projects the analysis variables onto the observation space; d is the innovation vector, $\mathbf{H}=\mathbf{y}^{o}-\mathbf{H} \mathbf{x}^{b}$, in which $\mathbf{y}^{o}$ is a vector of observations; $\mathbf{B}$ represents the background error covariance matrix; and $\mathbf{R}$ is the observation error covariance matrix. By differentiating Eq. (1) with respect to $\delta \mathbf{x}$ and then setting it to zero, we can obtain the optimal analysis:

$$
\mathbf{x}^{a}=\mathbf{x}^{b}+\mathbf{B} \mathbf{H}^{\mathrm{T}}\left(\mathbf{H B H}^{\mathrm{T}}+\mathbf{R}\right)^{-1} \mathbf{d} .
$$

For implementing a variational method in NWP, the estimation of $\mathbf{B}$ is necessary and important. The $\mathbf{B}$ matrix contains information about the weights of the control states and multivariate error correlation, which allows the spread of the information from the observations to the control states with balance (Bannister 2008a,b). Similar to Lin et al. (2017b), this study uses the NMC method (Parrish and Derber 1992) to compute the B matrix:

$$
\mathbf{B}=\overline{\boldsymbol{\eta} \boldsymbol{\eta}^{T}},
$$

where $\boldsymbol{\eta}$ is the difference of paired forecasts that have different initialization times but are valid at the same time, and the overbar denotes an average of forecast error samples. In a regional application [e.g., WRF data assimilation (WRFDA)], $\boldsymbol{\eta}$ is often obtained from paired 12- and 24-h forecasts [see a schematic diagram in Fig. 1 in Lin et al. (2017b)], as follows:

$$
\boldsymbol{\eta}=\mathbf{x}_{t+24 \mid t}^{f}-\mathbf{x}_{t+24 \mid t+12}^{f},
$$


(a) LAND USE CATEGORY
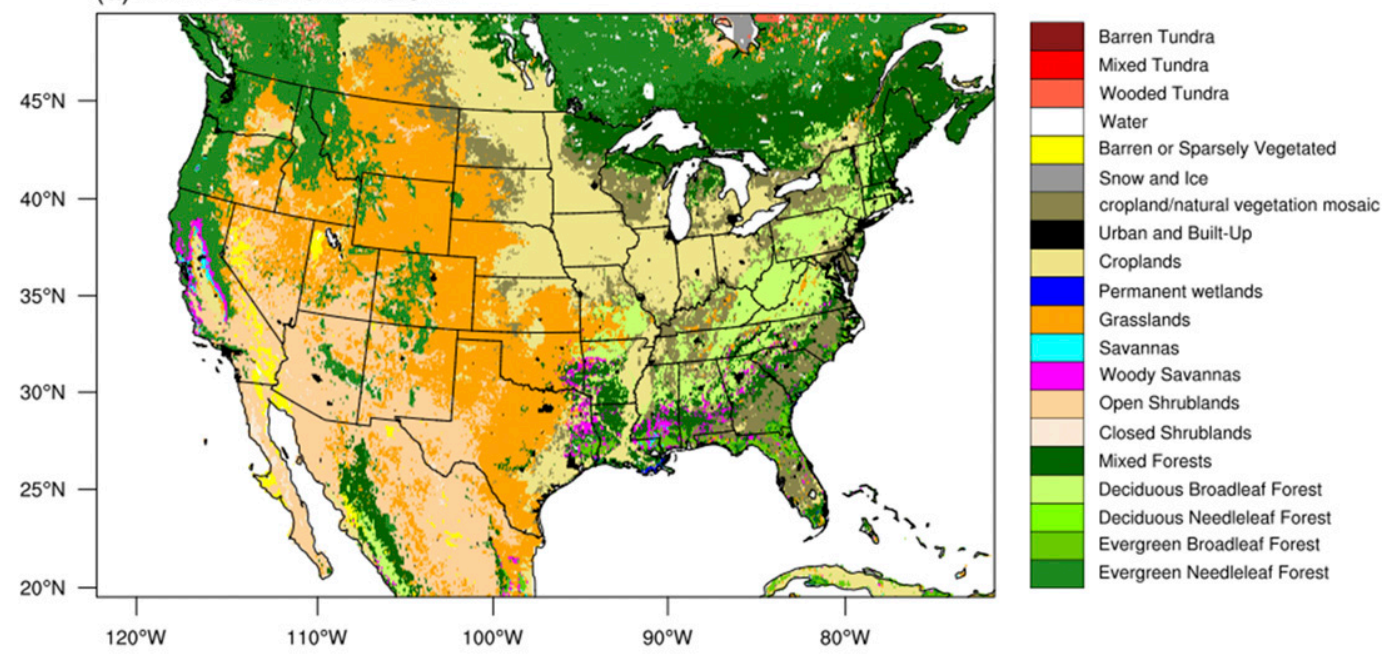

(b) DOMINANT SOIL CATEGORY
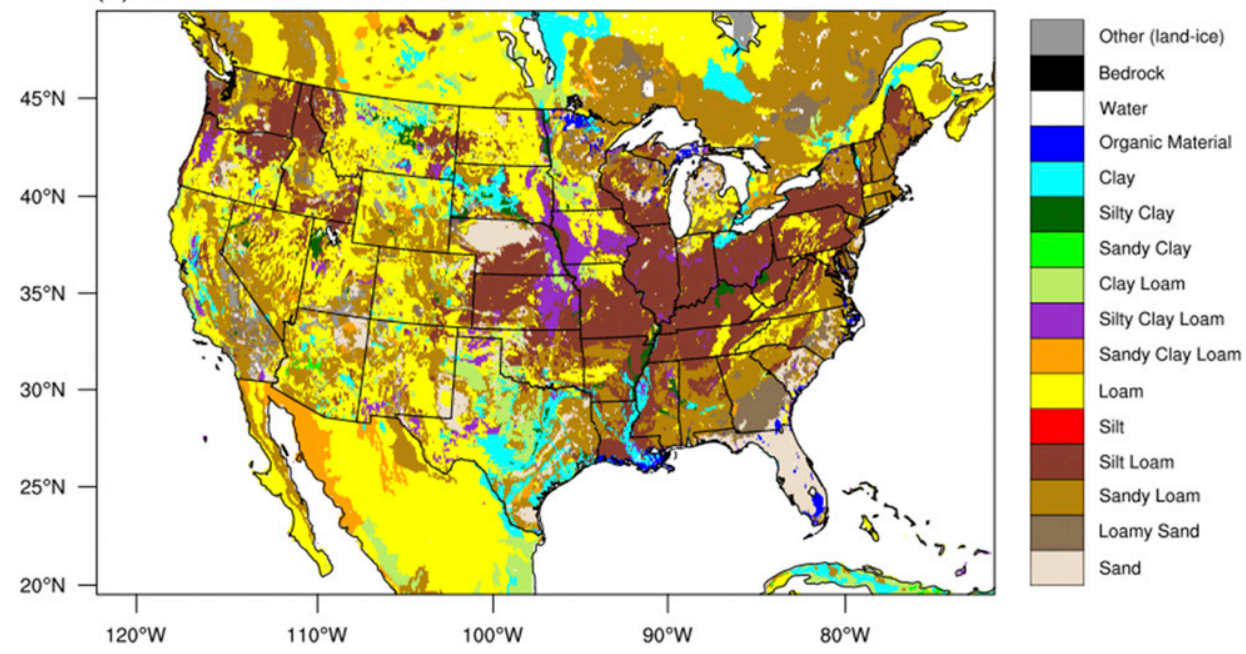

FIG. 1. The MODIS-based land-use and dominant soil categories of the study domain at a spatial resolution of $9 \mathrm{~km}$.

where each of the components on the right-hand side denotes the samples of 24- and 12-h forecasts with bias adjustment with respect to each control state.

\section{c. Scope of this study}

To investigate the impact of surface soil moisture on strongly coupled land-atmosphere data assimilation, this study uses atmospheric potential temperature $T$, specific humidity $Q$, zonal wind $U$, meridional wind $V$, and land surface soil moisture (SM) as control states. Although these atmospheric states may differ from those used in several operational NWP systems [e.g., the NCEP Global Forecast System uses derived variables such as streamfunction, velocity potential, temperature, relative humidity, and surface pressure; see Parrish and Derber (1992)], they are the main
WRF-ARW prognostic variables and control states in some atmospheric data assimilation systems (e.g., Barker et al. 2004, 2012; Shao et al. 2016). In addition, this study computes the B matrix of each pixel scale independently, without considering the impacts of neighboring pixels, and presents the results on a monthly scale to illustrate the spatial and temporal variability of the $\mathbf{B}$ matrix. We also investigate the diurnal variability of the $\mathbf{B}$ matrix.

We explain how the equations in section $2 b$ are used in this study. For simplicity, let us first use the toplayer soil moisture $\left(\mathrm{SM}_{1}\right)$ and the bottom-layer atmospheric states $\left(T_{1}, Q_{1}, U_{1}\right.$, and $\left.V_{1}\right)$ as an example. With these five variables, the symmetric and positive definite $\mathbf{B}$ matrix of a given pixel can be described as follows: 


$$
\mathbf{B}=\left[\begin{array}{ccccc}
\sigma_{\eta_{\mathrm{SM}_{1}}}^{2} & - & - & - & - \\
\operatorname{cov}\left(\eta_{T_{1}}, \eta_{\mathrm{SM}_{1}}\right) & \sigma_{\eta_{T_{1}}}^{2} & - & - & - \\
\operatorname{cov}\left(\eta_{Q_{1}}, \eta_{\mathrm{SM}_{1}}\right) & \operatorname{cov}\left(\eta_{Q_{1}}, \eta_{T_{1}}\right) & \sigma_{\eta_{Q_{1}}}^{2} & - & - \\
\operatorname{cov}\left(\eta_{U_{1}}, \eta_{\mathrm{SM}_{1}}\right) & \operatorname{cov}\left(\eta_{U_{1}}, \eta_{T_{1}}\right) & \operatorname{cov}\left(\eta_{U_{1}}, \eta_{Q_{1}}\right) & \sigma_{\eta_{U_{1}}}^{2} & - \\
\operatorname{cov}\left(\eta_{V_{1}}, \eta_{\mathrm{SM}_{1}}\right) & \operatorname{cov}\left(\eta_{V_{1}}, \eta_{T_{1}}\right) & \operatorname{cov}\left(\eta_{V_{1}}, \eta_{Q_{1}}\right) & \operatorname{cov}\left(\eta_{V_{1}}, \eta_{U_{1}}\right) & \sigma_{\eta_{V_{1}}}^{2}
\end{array}\right]
$$

where the diagonal elements are the autocovariance of the forecast error of the explained variables, and the offdiagonal elements are the covariance. Note that when considering the atmospheric states of the 40 layers (see section $2 \mathrm{a}$ ) and only top-layer soil moisture, the dimension of the actual computed $\mathbf{B}$ matrix expands from $5 \times 5$ to $161 \times 161$. The matrix of this example can be decomposed as $\mathbf{B}=\mathbf{\Sigma} \mathbf{C} \mathbf{\Sigma}$, as follows:

$\boldsymbol{\Sigma}=\left[\begin{array}{ccccc}\sigma_{\eta_{\mathrm{SM}_{1}}} & 0 & 0 & 0 & 0 \\ 0 & \sigma_{\eta_{T_{1}}} & 0 & 0 & 0 \\ 0 & 0 & \sigma_{\eta_{Q_{1}}} & 0 & 0 \\ 0 & 0 & 0 & \sigma_{\eta_{U_{1}}} & 0 \\ 0 & 0 & 0 & 0 & \sigma_{\eta_{V_{1}}}\end{array}\right]$ and

$\mathbf{C}=\left[\begin{array}{ccccc}1 & \rho_{\eta_{\mathrm{SM}_{1}}, \eta_{T_{1}}} & \rho_{\eta_{\mathrm{SM}_{1}}, \eta_{Q_{1}}} & \rho_{\eta_{\mathrm{SM}_{1}}, \eta_{U_{1}}} & \rho_{\eta_{\mathrm{SM}_{1}}, \eta_{V_{1}}} \\ \rho_{\eta_{T_{1}}, \eta_{\mathrm{SM}_{1}}} & 1 & \rho_{\eta_{T_{1}}, \eta_{Q_{1}}} & \rho_{\eta_{T 1}, \eta_{U_{1}}} & \rho_{\eta_{T_{1}}, \eta_{V_{1}}} \\ \rho_{\eta_{Q_{1}}, \eta_{\mathrm{SM}_{1}}} & \rho_{\eta_{Q_{1}}, \eta_{T_{1}}} & 1 & \rho_{\eta_{Q_{1}}, \eta_{U_{1}}} & \rho_{\eta_{Q_{1}}, \eta_{V_{1}}} \\ \rho_{\eta_{U_{1}}, \eta_{\mathrm{SM}_{1}}} & \rho_{\eta_{U_{1}}, \eta_{T_{1}}} & \rho_{\eta_{U_{1}}, \eta_{Q_{1}}} & 1 & \rho_{\eta_{U_{1}}, \eta_{V_{1}}} \\ \rho_{\eta_{V_{1}}, \eta_{\mathrm{SM}_{1}}} & \rho_{\eta_{V_{1}}, \eta_{T_{1}}} & \rho_{\eta_{V_{1}}, \eta_{Q_{1}}} & \rho_{\eta_{V_{1}}, \eta_{U_{1}}} & 1\end{array}\right]$,

where $\sigma$ is the error standard deviation of the five explained variables, and $\rho$ is the error correlation between different variables. A covariance matrix illustrates the sensitivity of how two different analysis states are connected and affect each other directly. For example, assimilation of surface soil moisture data can correct the specific humidity via the product of $\sigma_{\eta_{\mathrm{SM}_{1}}} \rho_{\eta_{\mathrm{SM}_{1}}, \eta_{Q_{1}}} \sigma_{\eta_{Q_{1}}}$, where $\rho_{\eta_{\mathrm{SM}_{1}}, \eta_{Q_{1}}}$ is particularly important. When $\rho_{\eta_{\mathrm{SM}_{1}}, \eta_{Q_{1}}}=1$, the correction on $\mathrm{SM}_{1}$ will be directly reflected on $Q_{1}$, while $Q_{1}$ is not affected at all as $\rho_{\eta_{\mathrm{SM}_{1}}, \eta_{Q_{1}}}=0$. Analogously, $Q_{1}$ is also affected by the assimilation of near-surface temperature data via $\rho_{\eta_{T_{1}}, \eta_{Q_{1}}}$. Therefore, the main focus of this study is to compare the magnitude of the error correlation between different control states.

\section{d. Experiment design}

Over the study domain (see Fig. 1), we use the NCEP Final Analysis (FNL) dataset (NWS 2000, 2015) to obtain the initial and lateral boundary conditions for the WRFNoah experiments. To compute the $\mathbf{B}$ matrix, we initialize WRF-Noah simulations at 0000 and 1200 UTC nearly every day from 2015 to 2017 to obtain 12- and 24-h forecasts. It is noted that prior to July 2015 we use $1^{\circ}$ NCEP FNL data, while after August 2015 we use $0.25^{\circ}$ NCEP FNL data. This change is due to the availability of higher-resolution $0.25^{\circ}$ FNL data starting in July 2015. We have empirically found that the difference between using the $1^{\circ}$ and the $0.25^{\circ} \mathrm{NCEP}$ FNL datasets on the $\mathbf{B}$ matrix is generally small and negligible. Like Lin et al. (2017b), to ensure the robustness of the results with a sufficient sample size, we present the $\mathbf{B}$ matrix on a monthly scale. Every month, we compute the $\mathbf{B}$ matrix by using 54 pairs of 12 - and 24-h forecasts (i.e., from the simulations initialized at 0000 and 1200 UTC during the 1st and 27 th day of the month) to show the "all time" results. For the daytime (nighttime) results, we obtain 27 pairs from forecasts valid at 0000 UTC (1200 UTC). In this case, 0000 UTC corresponds to 1800 central standard time locally over the United States, and we consider that the forecasts valid at 0000 UTC will contain the model errors during the daytime from 0600 to 1800 local time.

In the computation of the $\mathbf{B}$ matrix, as the WRF Model adopts the Arakawa staggering $\mathrm{C}$ grid, winds are computed at the sides rather than at the center of the model grid. To obtain the zonal (meridional) wind forecast samples, we use the winds on the left (bottom) side of a grid. We expect that the selected wind samples should well represent the winds over the center of a grid. In addition, we exclude samples over the pixels characterized as water (see Fig. 1) or frozen soils. Over frozen soils, modeled soil moisture has little variability, and satellite soil moisture such as that from SMAP is not retrieved [see Lin and Bras (2017)]. We gather the soil temperatures from the top-10-cm soil from the initial conditions of all the WRF-Noah simulations. Over a pixel, whenever at least one out of 54 samples shows surface soil temperature of less than $275 \mathrm{~K}$ during a month, we label it as frozen soil.

\section{Results and discussions}

Solar heating is large during the summertime, and it leads to strong land-atmosphere interactions. In this process, soil moisture can directly affect air temperature and 
ALL
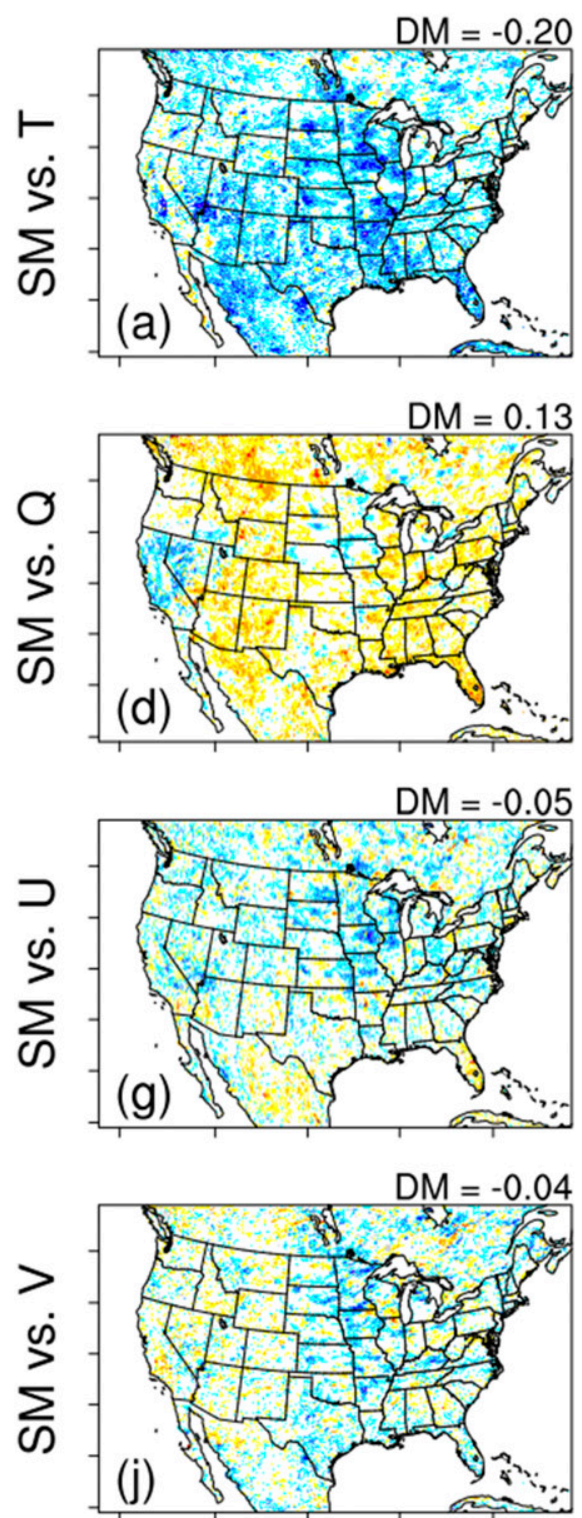

DAY
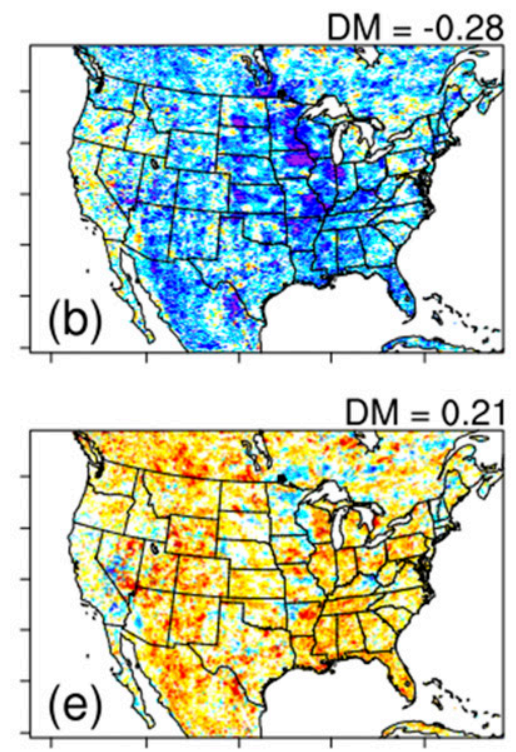

(e)

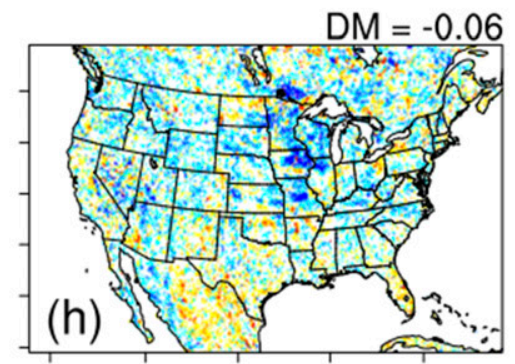

(h)

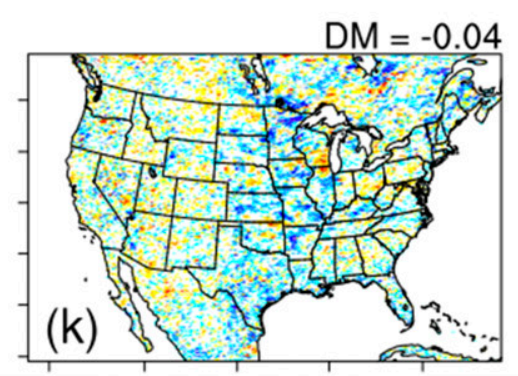

NIGHT
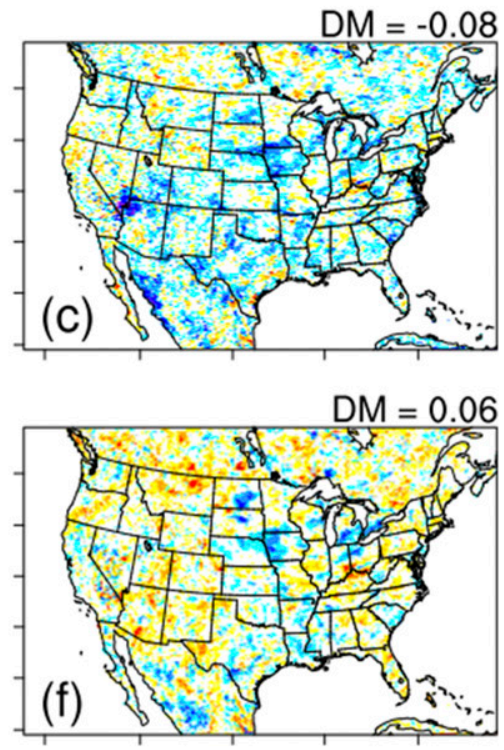

$\mathrm{DM}=-0.03$
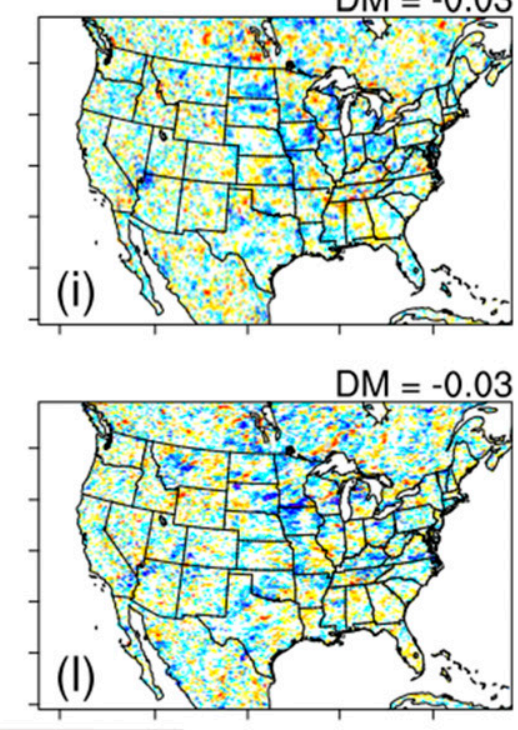

$\begin{array}{ll}-0.8 & -0.6\end{array}$

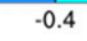

\section{Correlation}

FIG. 2. The error correlations between top-layer soil moisture (SM) and bottom-layer (a)-(c) potential temperature $T$, (d)-(f) specific humidity $Q$, (g)-(i) zonal wind $U$, and (j)-(1) meridional wind $V$ during Jul 2016 . The forecast samples valid at 0000 and 1200 UTC are categorized at the "DAY" and "NIGHT" time results, and the "ALL" time results are computed based on all the samples. Domain-mean (DM) values are computed based on the results of warm land pixels without considering the 10 -grid-wide boundary. The $95 \%$ confidence intervals of the $\mathrm{DM}$ values vary from $\mathrm{DM} \pm 0.001$ to $\mathrm{DM} \pm 0.0015$.

humidity via sensible and latent heat fluxes during model integration. Meanwhile, soil moisture is affected by precipitation, downward radiation, and near-surface temperature, humidity, and wind in the atmosphere. We first use the results in July to examine the significance of the covariance between the soil moisture and atmospheric states (section 3a). Then, we explore the temporal variability of the $\mathbf{B}$ matrix by comparing the results for each month from 2015 to 2017 (section 3b). Note that when computing the domain-mean values of the error standard deviation and correlation, we exclude the samples over the 10-gridwide boundary to reduce the impact of boundary modeling 


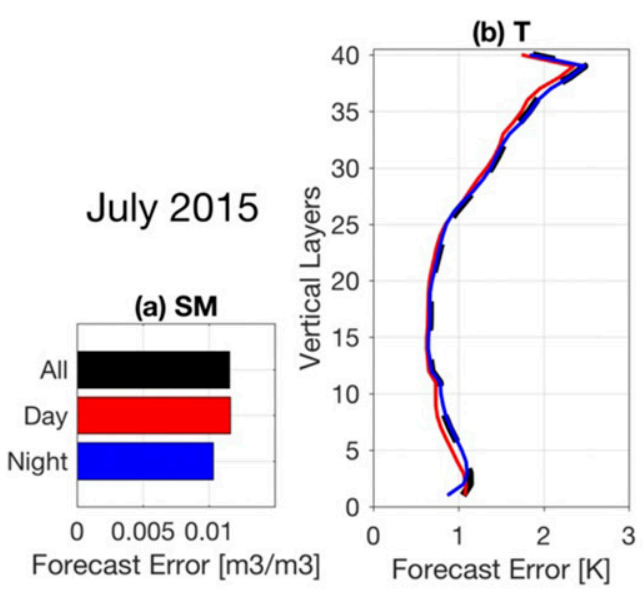

(g) $\mathrm{T}$

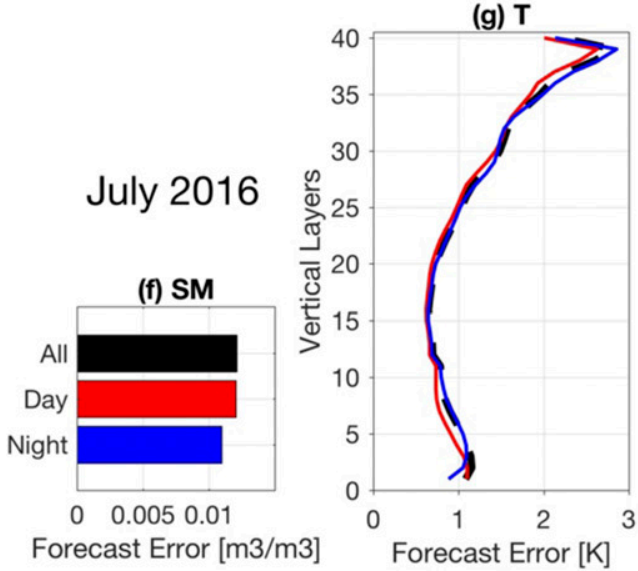

(l) $\mathrm{T}$

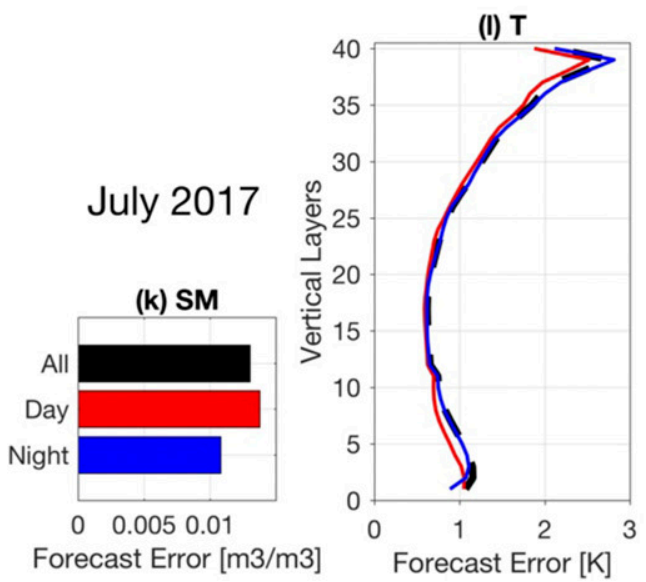

(c) $Q$

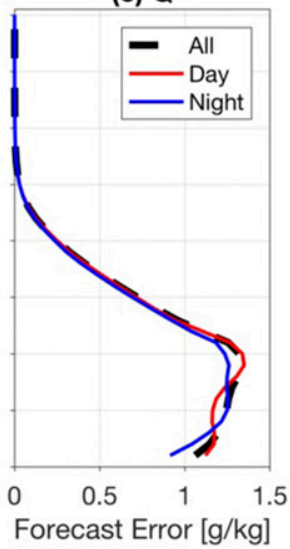

(h) Q

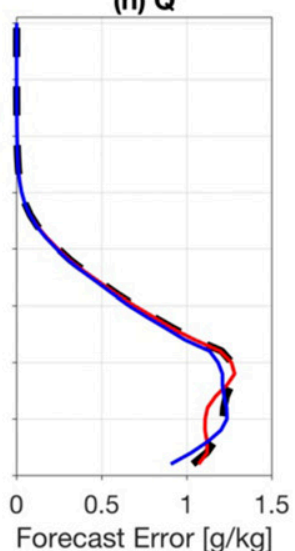

(m) Q

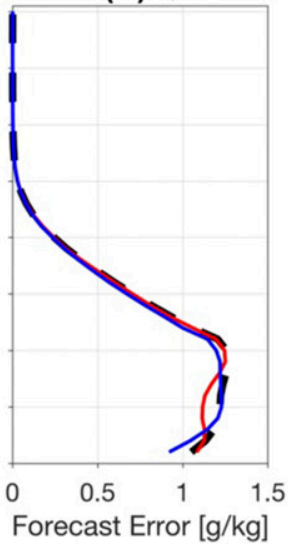

(d) $U$

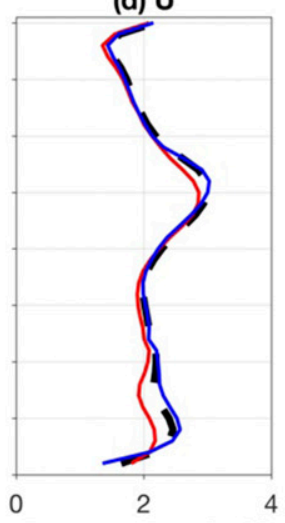

Forecast Error $[\mathrm{m} / \mathrm{s}]$

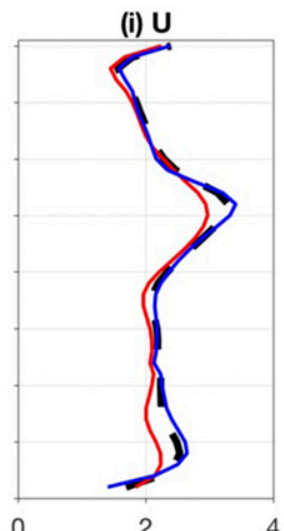

Forecast Error [m/s]

(n) U

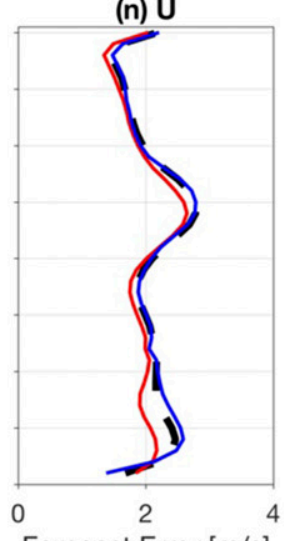

(e) $\mathbf{V}$

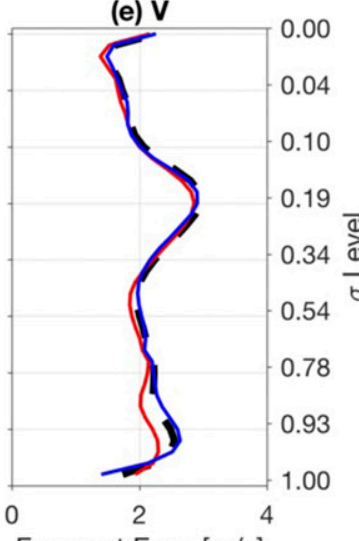

Forecast Error [m/s]

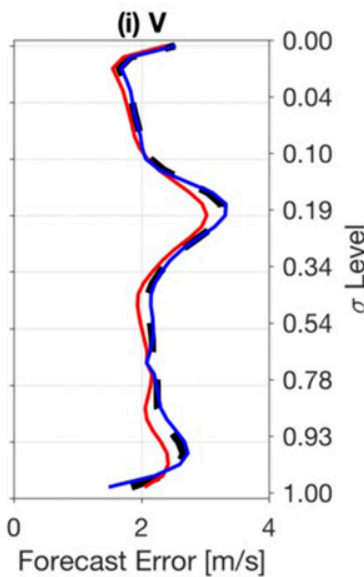

(o) V

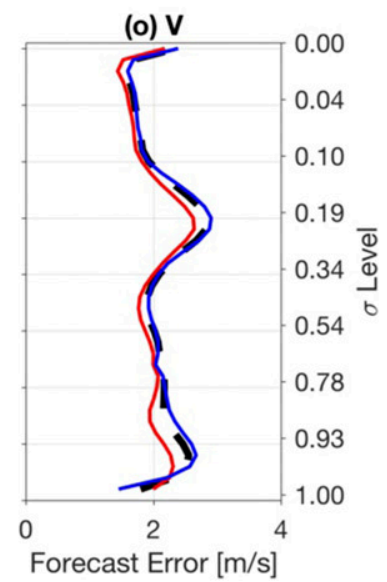

FIG. 3. Horizontal DM values of the forecast errors in the top-10-cm SM and atmospheric $T, Q, U$, and $V$ during July from 2015 to 2017.

anomalies on the B matrix. Water and frozen pixels (see section 2d) are also not included in the computation of the domain-mean values.

\section{a. Preliminary investigation of the $\mathbf{B}$ matrix in July}

Figure 2 shows the error correlation between the top-10-cm soil moisture and bottom-layer atmospheric states from all the samples as well as from daytime- and nighttime-only samples in July 2016. As is evident, in July 2016, the results show a negative error correlation between soil moisture and potential temperature but a positive correlation between soil moisture and air humidity. Generally speaking, the correlation is seen nearly everywhere over the study domain, and the daytime 

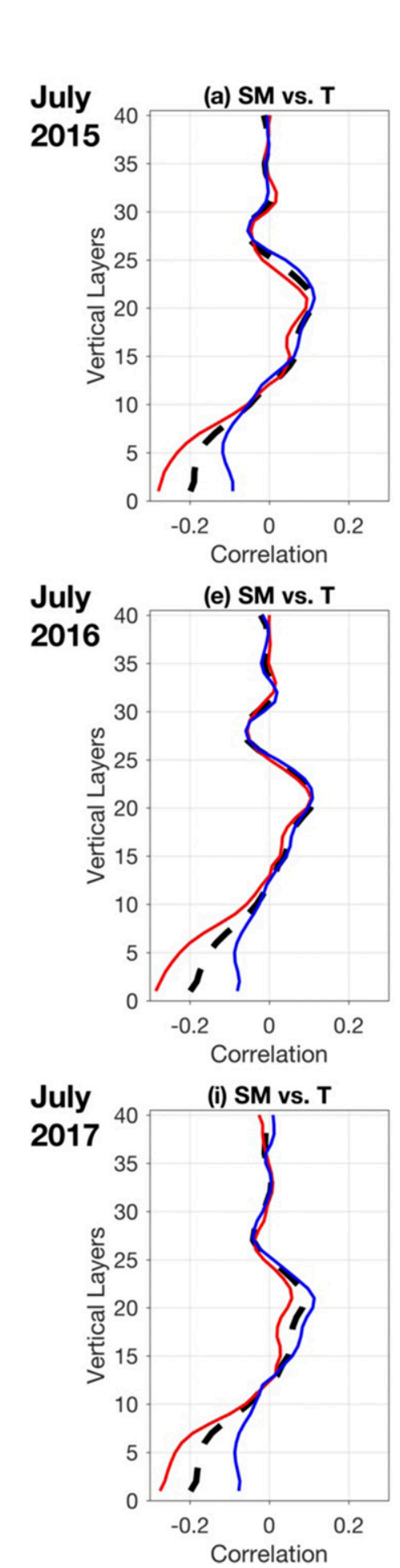

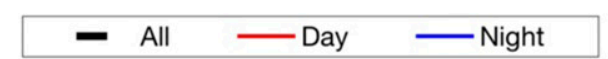

(b) SM vs. Q

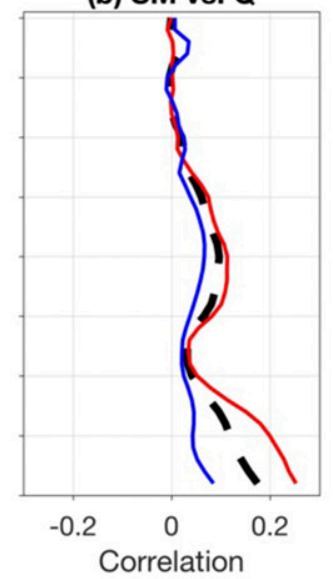

(f) SM vs. $Q$

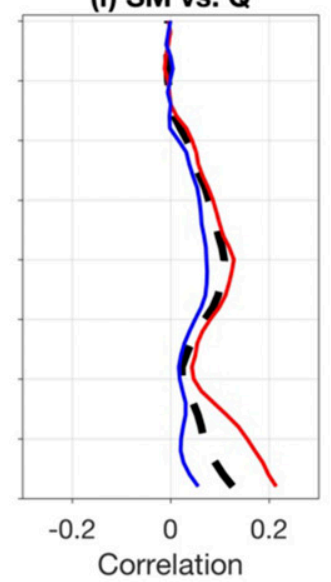

(i) SM vs. Q

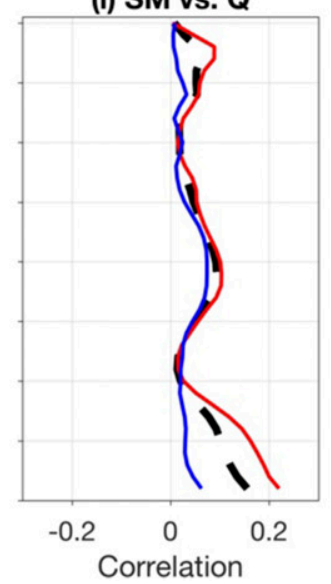

(c) SM vs. U

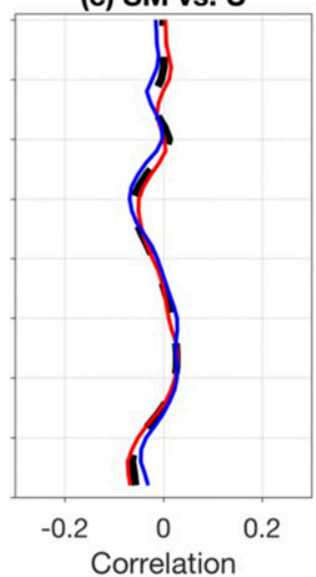

(g) SM vs. U

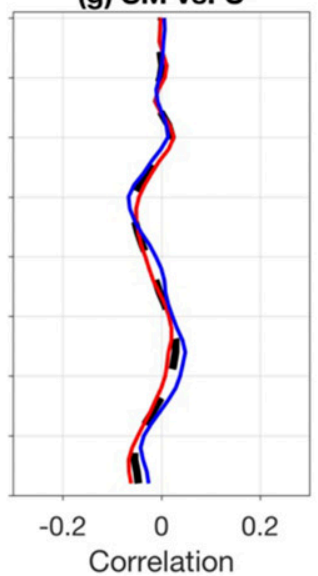

(k) SM vs. U

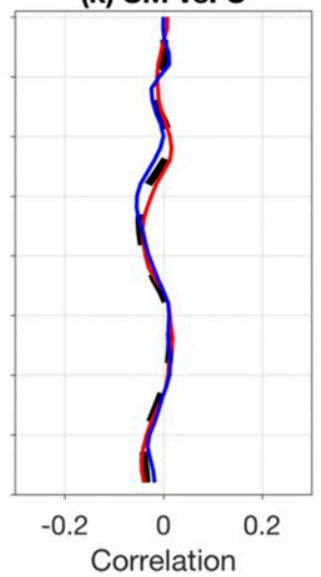

(d) SM vs. V

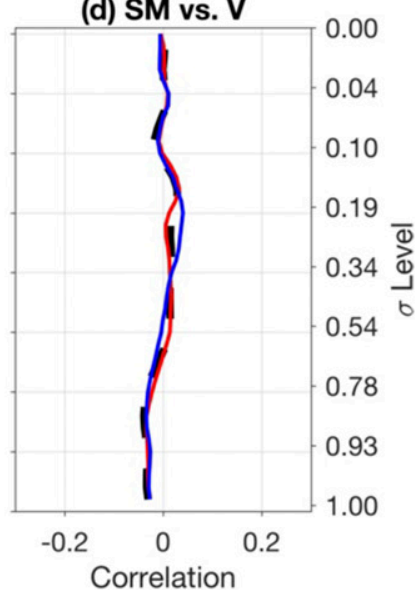

(h) SM vs. V
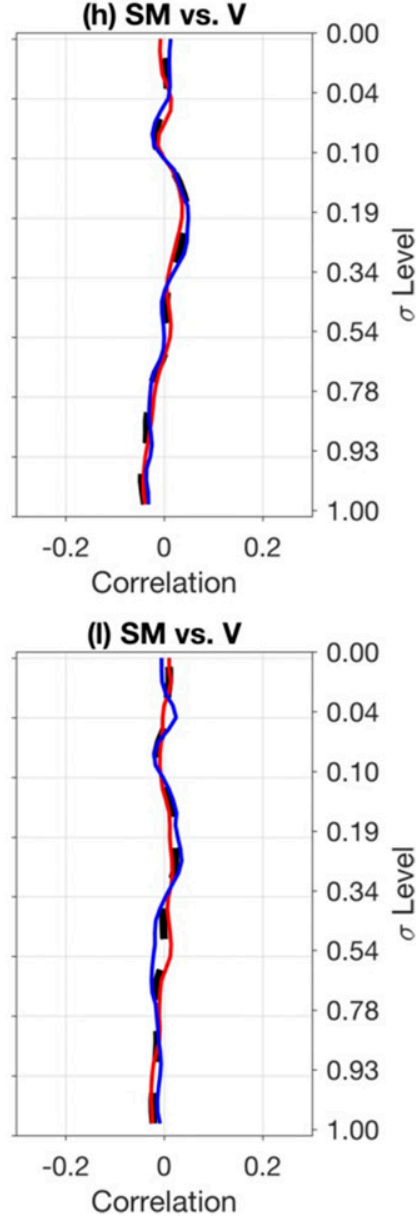

FIG. 4. Horizontal DM values for the error correlation between the top-10-cm WRF-Noah SM and atmospheric states including $T, Q, U$, and $V$ during July from 2015 to 2017.

correlation is larger than the nighttime correlation. This observation agrees with that of Mahfouf (1991). In addition, we find no substantial correlation between soil moisture and winds according to the maps and domain-mean values. As the error correlation between soil moisture and some atmospheric variables exists, the results preliminarily suggest the potential of soil moisture data assimilation to improve the atmospheric states. 


\section{ALL}
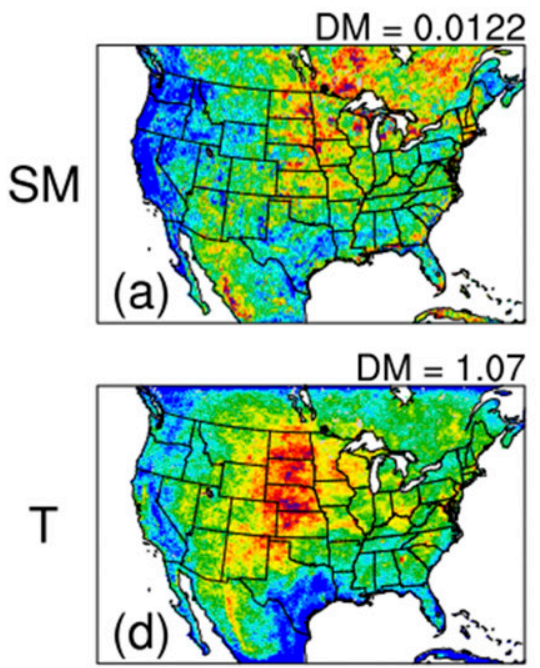

$\mathrm{DM}=1.05$

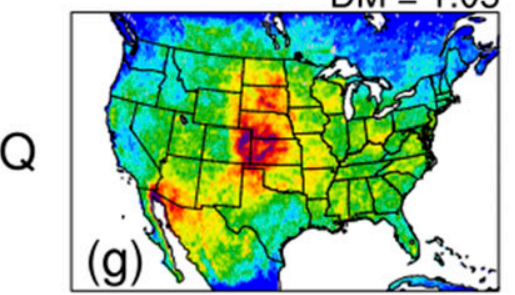

$D M=1.67$
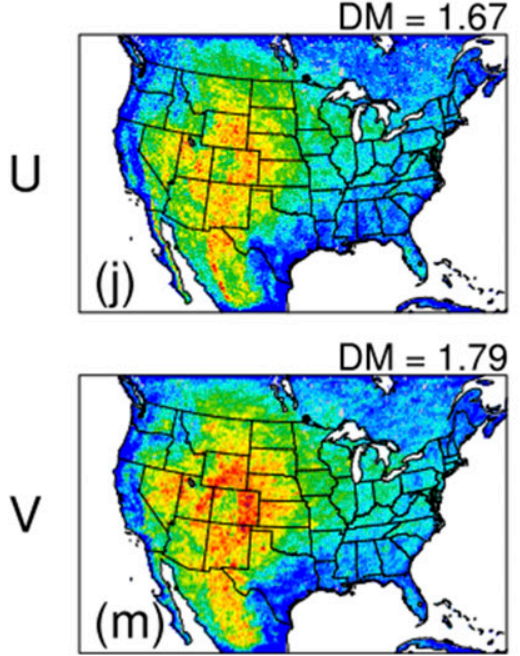

DAY
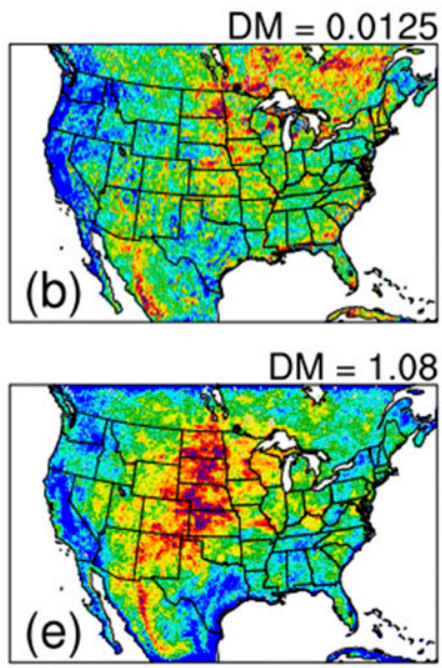

$\mathrm{DM}=1.09$

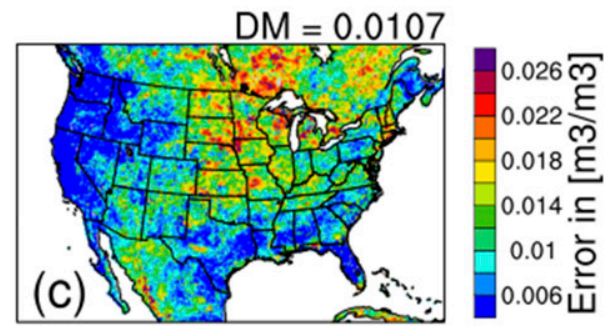

NIGHT
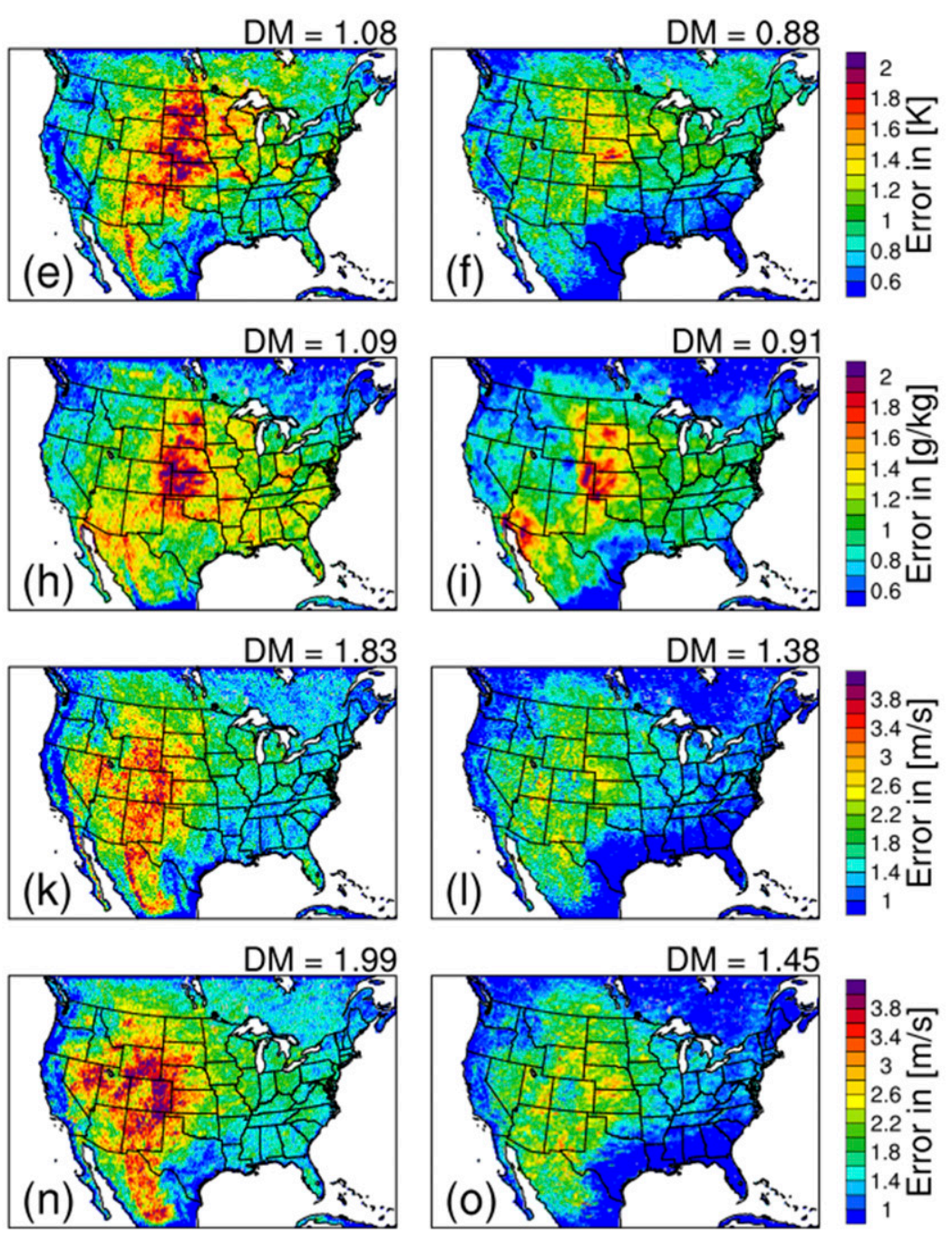

FIG. 5. The spatial distribution of the forecast errors $\sigma$ averaged over the results during July from 2015 to 2017 for (a)-(c) land surface SM and near-surface (d)-(f) $T$, (g)-(i) $Q$, (j)-(l) $U$, and (m)-(o) $V$. DM values are computed based on the results over the warm land pixels without considering the 10 -grid-wide boundary.

We further explore whether the $\mathbf{B}$ matrix shows any variability from year to year. By examining the maps of error standard deviation and correlation over different variables and vertical layers in July from 2015 to 2017, we see that local-scale variability occurs (not shown). However, the overall large-scale pattern of the $\mathbf{B}$ matrix is very similar for the error standard deviation of each variable and the error correlation between the variables in different years. Figure 3 shows the domain-mean values of the error standard deviation (i.e., forecast error) of top-10-cm soil moisture and the atmospheric states in July from 2015 to 2017 . The results demonstrate the similarity 
ALL
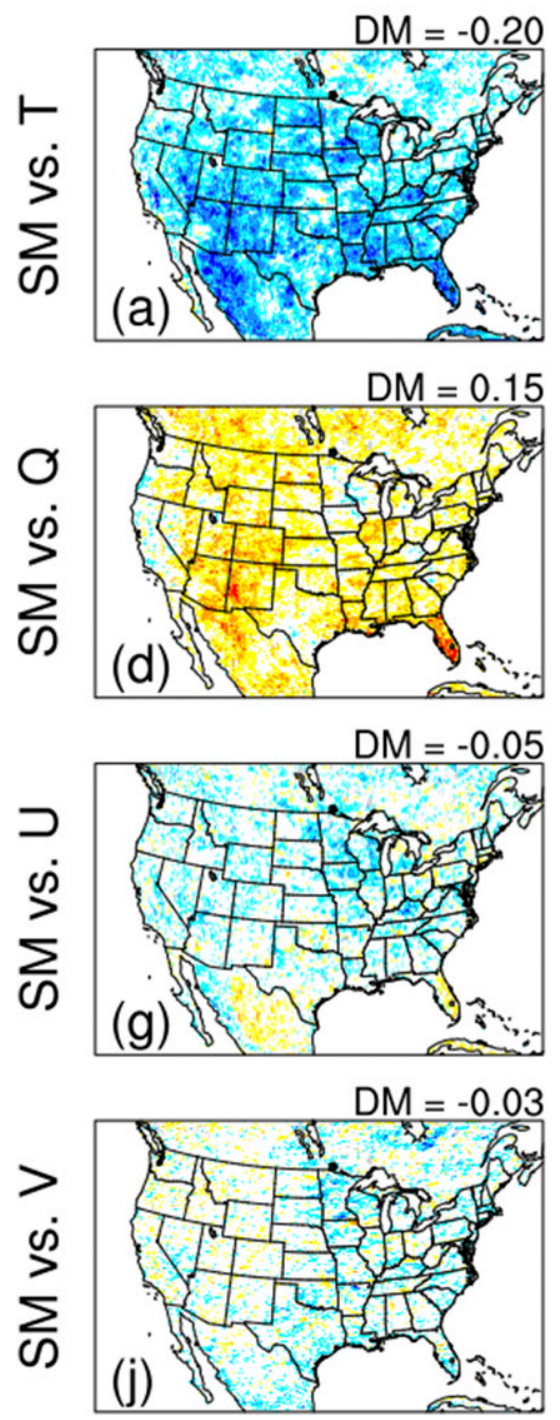

DAY
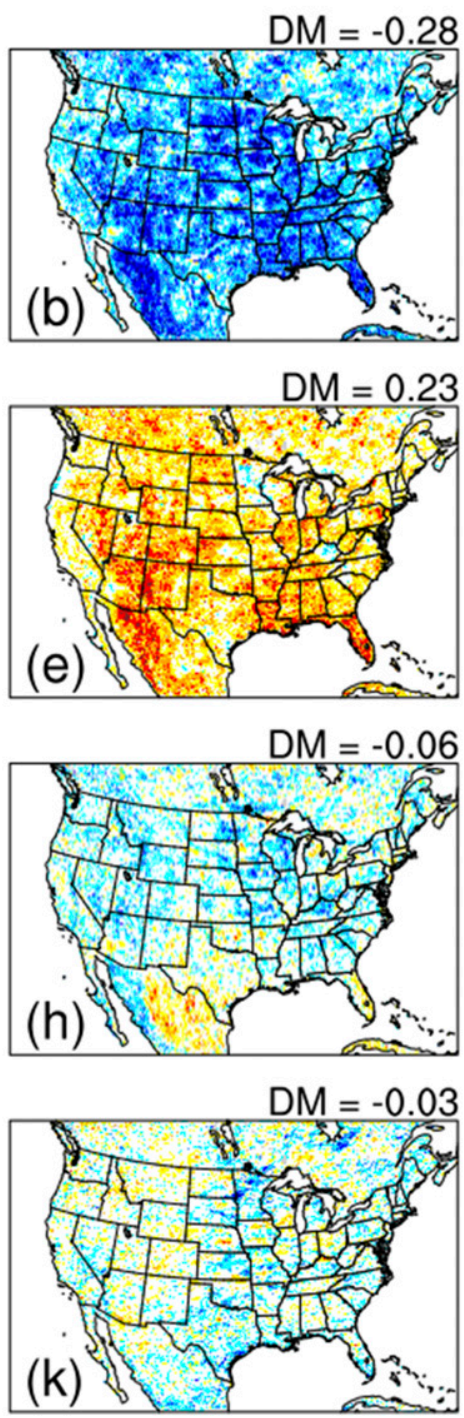

NIGHT
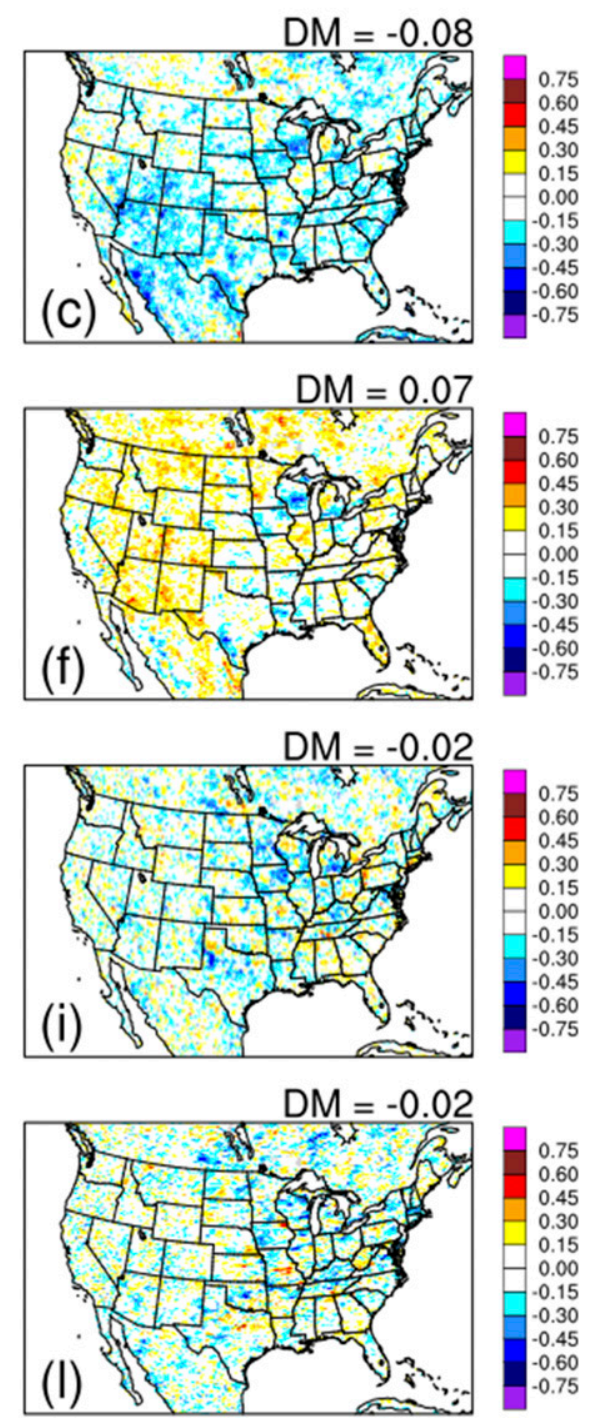

FIG. 6. The spatial distribution of the error correlation $\rho$ averaged over the results during July from 2015 to 2017 , including the error correlations between land surface soil moisture and near-surface (a)-(c) $T$, (d)-(f) $Q$, (g)-(i) $U$, and (j)-(l) $V$. DM values are reported. The $95 \%$ confidence intervals of the $\mathrm{DM}$ values vary from $\mathrm{DM} \pm 0.0005$ to $\mathrm{DM} \pm 0.001$.

of summertime (July) forecast errors in different years. In the lowest 10 atmospheric layers, the magnitudes of the forecast errors are approximately $0.8-1 \mathrm{~K}$ for potential temperature, $1-1.2 \mathrm{~g} \mathrm{~kg}^{-1}$ for specific humidity, and $2 \mathrm{~m} \mathrm{~s}^{-1}$ for winds. It is noted that the errors peak approximately at the stratosphere for potential temperature and at the top of the troposphere for winds. Explanation of the errors over high elevations is beyond the scope of this study and requires further research.

Figure 4 shows the domain-mean values of the error correlation between the surface soil moisture and the atmospheric states during July from 2015 to 2017. As in Fig. 3, we see that the results show little variability among different years. In addition, we can see that the error correlation between soil moisture and temperature/ humidity is quite large over the bottom 10 layers. It makes sense that the error correlation decreases with the model level, indicating the decreasing impact of soil moisture data assimilation on higher-level atmospheric states. For winds, it appears that the error in soil moisture is simply not linked with that in winds during the summer.

Since we have shown the similarity of the $\mathbf{B}$ matrix in different years, here we average the $\mathbf{B}$ matrix in July over three years from 2015 to 2017 to obtain maps with better representativeness. Figure 5 shows the 3-yr average error standard deviation of the top-layer soil 
ALL
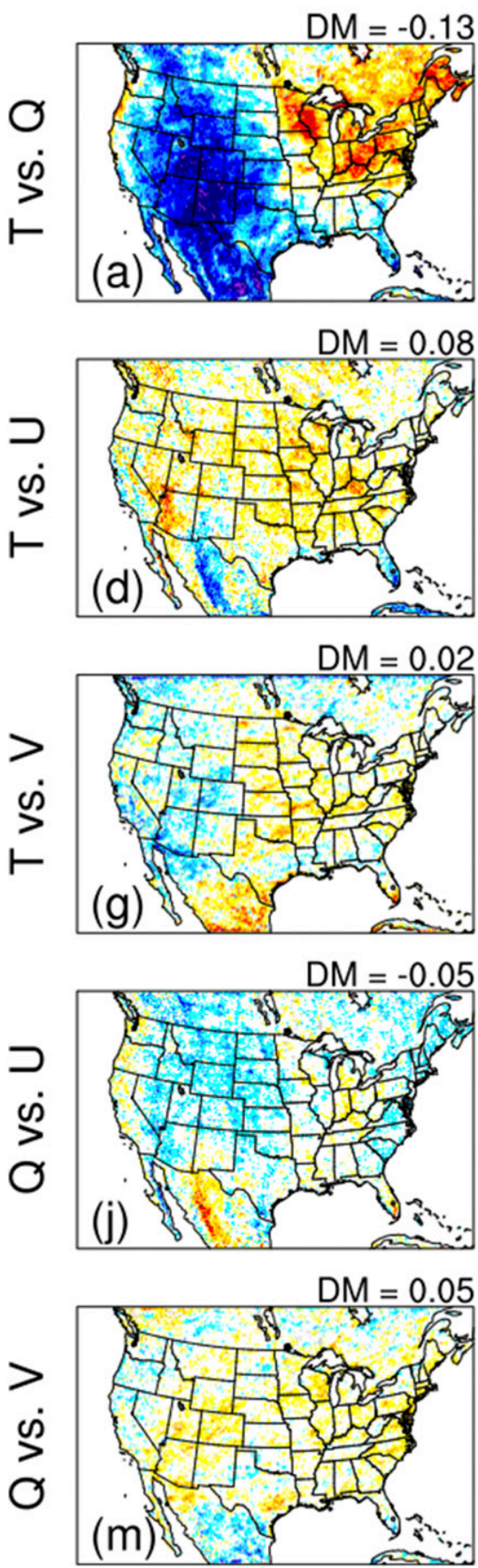

DAY
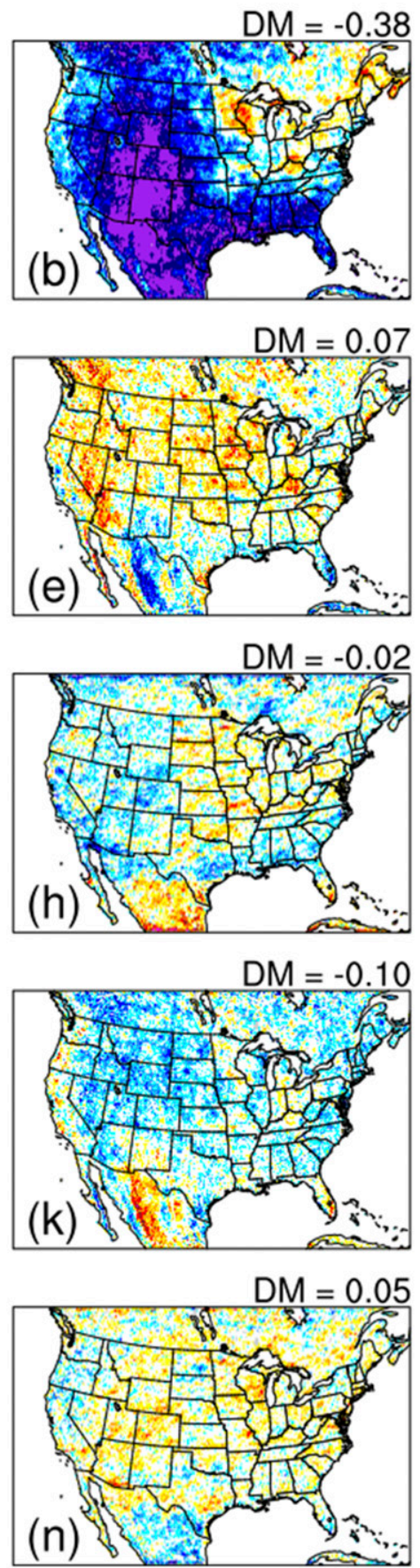

NIGHT
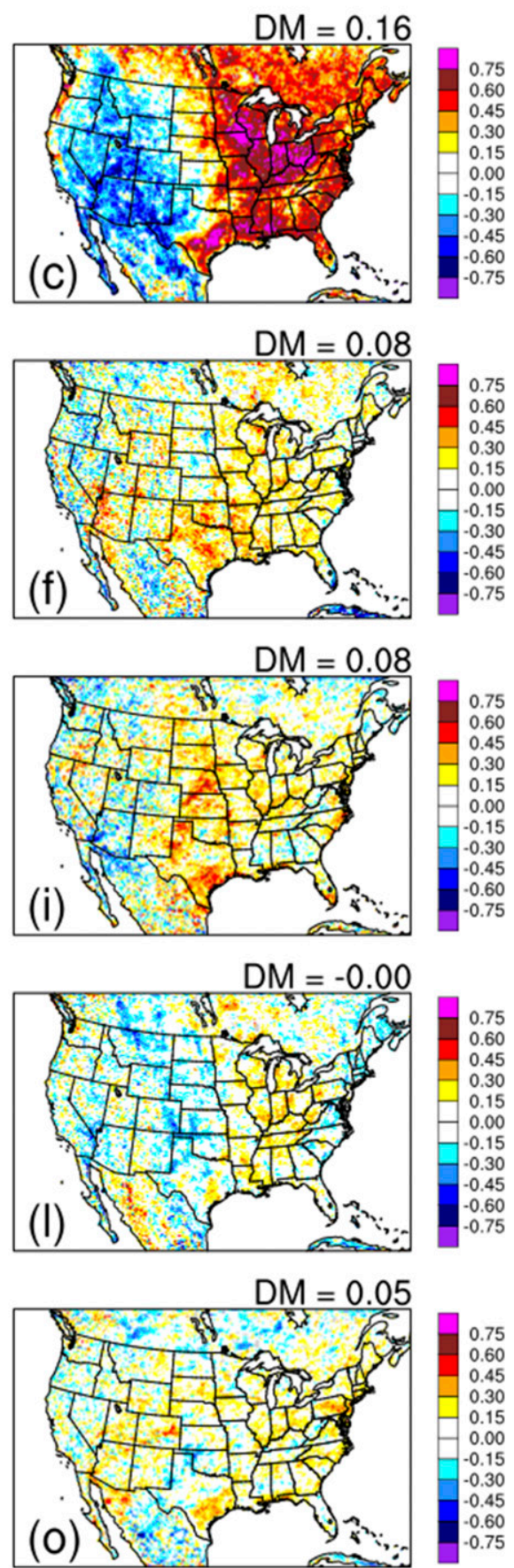

FIG. 7. As in Fig. 6, but for the error correlation between near-surface atmospheric states. The $95 \%$ confidence intervals of the DM values vary approximately from $\mathrm{DM} \pm 0.0007$ to $\mathrm{DM} \pm 0.002$.

moisture and bottom-layer atmospheric states. The errors are found to be relatively large over approximately the Midwest for soil moisture, the Great Plains for temperature and humidity, and the Intermountain West for winds. The pattern of the soil moisture background error agrees well with the results of Lin et al. (2017b), who explained in detail that the pattern is partially attributed to the climatology of precipitation and soil moisture. Large errors in temperature and humidity are likely affected by strong land-atmosphere interactions 

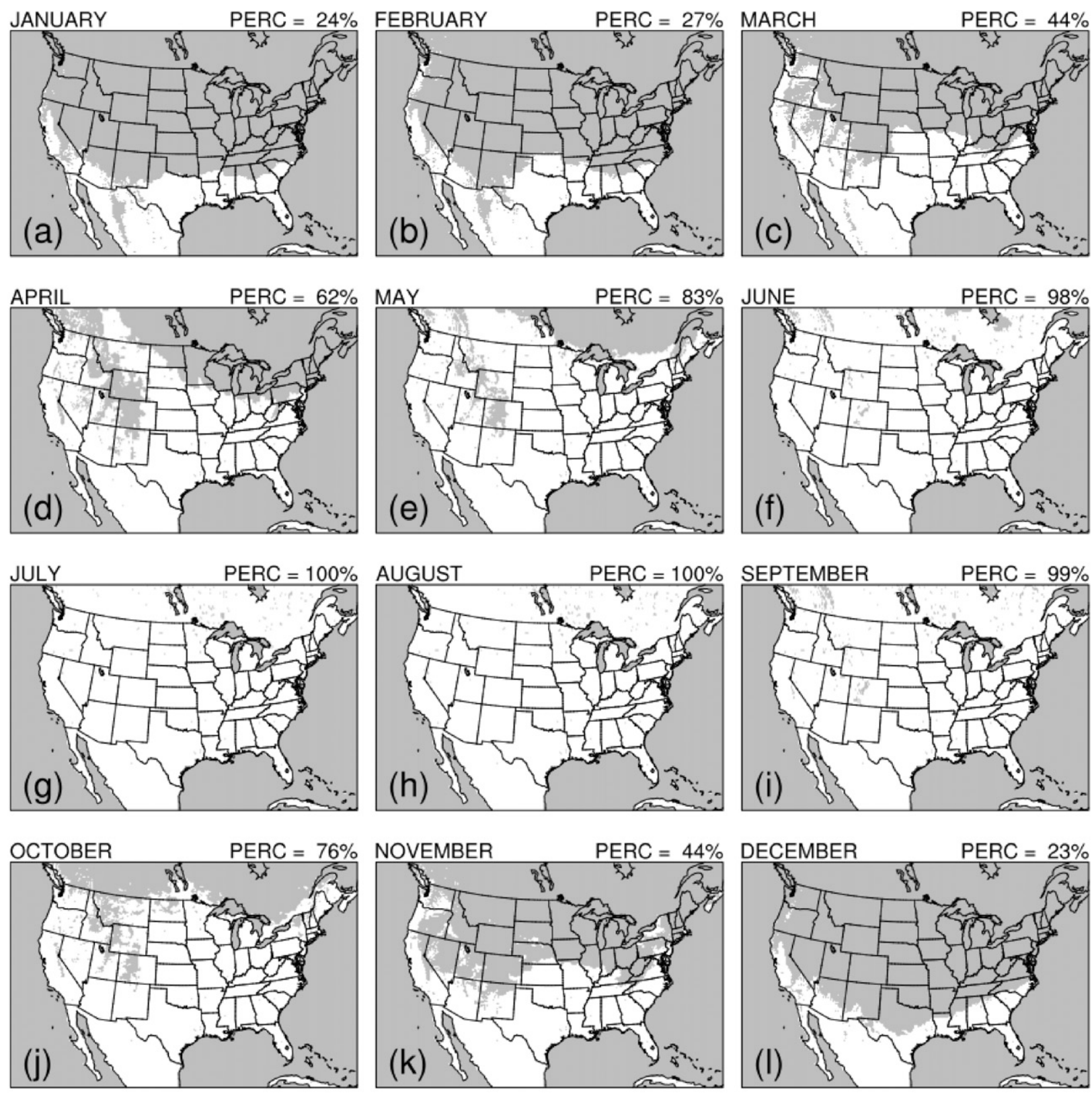

Warm Land Pixels

Cold Land or Water Pixels

FIG. 8. The spatial extent of warm land pixels during each month of 2016. The classification of cold pixels is according to the model surface soil temperature data, described in section $2 \mathrm{~d}$. The percentage of warm land pixels over land (PERC) is reported.

over the Great Plains (Koster et al. 2004, 2006). In addition, the large wind error over the West may be relevant to complex terrain (see Zhang et al. 2013; Pu 2017). Further investigations of the mechanism beyond the pattern of the errors are needed.

Figure 6 shows the 3-yr average error correlation between the top-layer soil moisture and bottom-layer atmospheric states in July. The results are very similar to those in Fig. 2 and further demonstrate that the error correlation between soil moisture and temperature/humidity is strong everywhere during the daytime, while there is no obvious correlation between soil moisture and winds. The maps in Figs. 5 and 6 together provide a clear viewpoint of the $\mathbf{B}$ matrix, implying that assimilation of soil moisture can impact the temperature and humidity analyses everywhere, particularly over the 


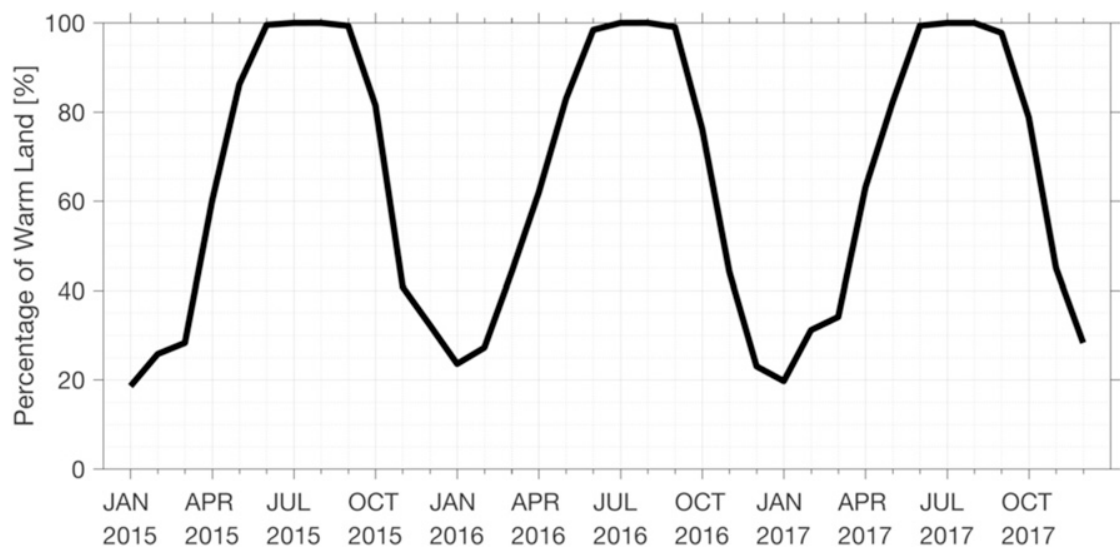

FIG. 9. The percentage of warm land pixels over land during each month from 2015 to 2017. The classification of nonwarm pixels is described in section $2 \mathrm{~d}$.

Great Plains, due to the large errors in the soil moisture, temperature, and humidity forecasts. Note that we show only the maps of the bottom layer, as the spatial pattern is generally similar in the upper layers but with decreasing magnitude.

To compare the relative importance of the error correlation between soil moisture and the atmospheric states and that between different atmospheric states, we compute the 3-yr average error correlation between bottom-layer atmospheric states in July (Fig. 7). Figure 7 shows that the error correlation is on average significant between the errors in temperature and humidity, while it is very small $(\rho<0.1)$ for the errors in temperature/ humidity versus winds. When comparing Figs. 6 and 7, we can see that the error correlation between soil moisture and temperature/humidity is on average comparable and even stronger than that between temperature and humidity. The results suggest that the assimilation of soil moisture data could provide cross-variable impacts comparable to the assimilation of conventional temperature and humidity observations when both types of data are available in time and space. Nonetheless, the pattern of the error correlation between temperature and specific humidity shows a very strong contrast between the East and West as well as between daytime and nighttime. During the daytime, the error correlation is large and negative in the West. On the other hand, it is large but positive in the East during the nighttime. This spatial pattern may be attributed to regional aridity. The contrasting spatial pattern is similar to that in Tuttle and Salvucci (2016), who indicated that the western arid areas show a positive soil moisture and next-day precipitation feedback (i.e., the higher the soil moisture, the higher the likelihood of precipitation occurrence) while the eastern humid and vegetated areas show a negative feedback. The underlying physics of this contrasting pattern are worth further investigation. Finally, although the domain-mean values between the

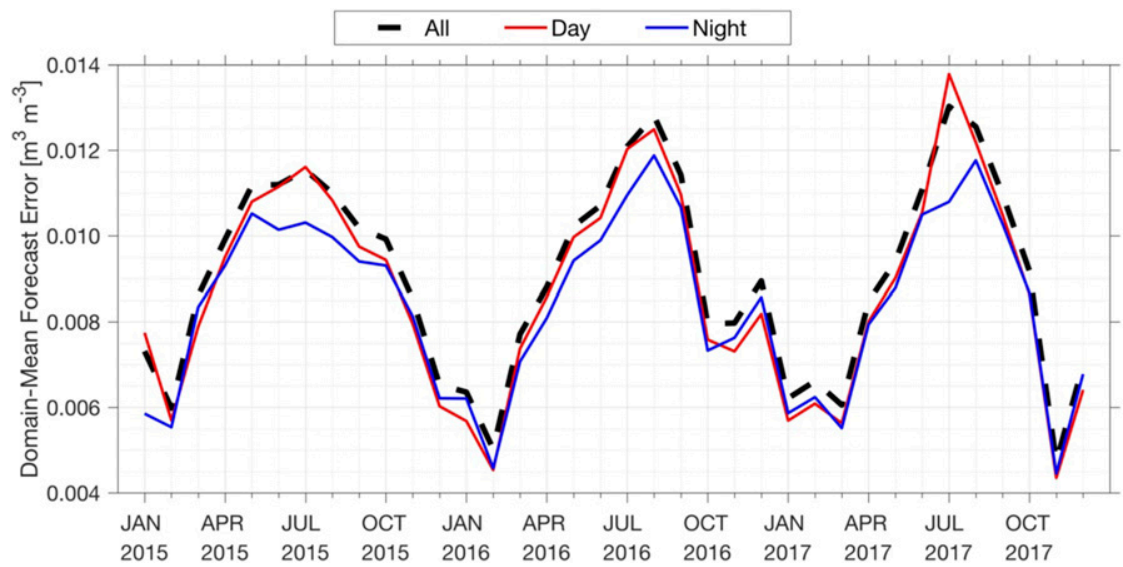

FIG. 10. The DM forecast error of the top-layer soil moisture during each month from 2015 to 2017. 


\section{(a) All}

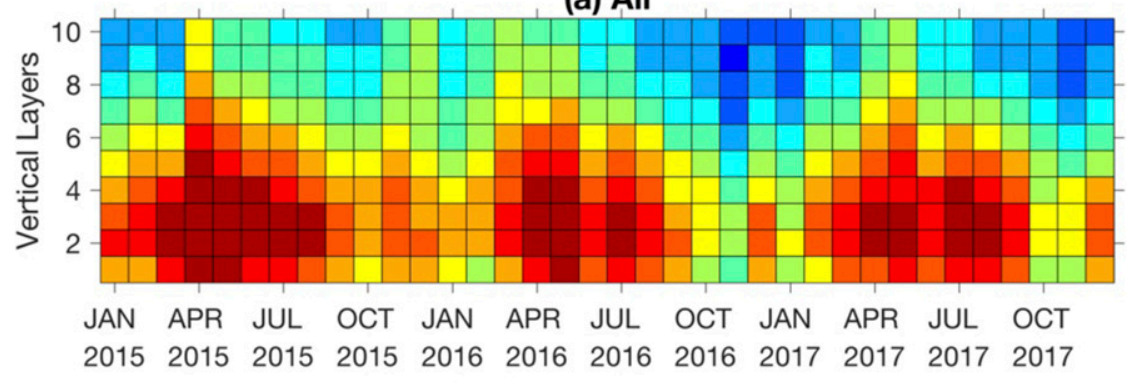

(b) Day

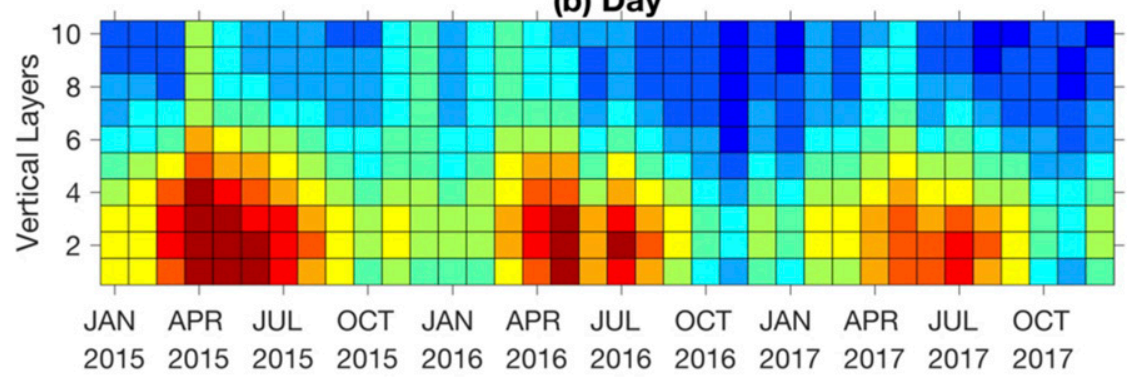

(c) Night

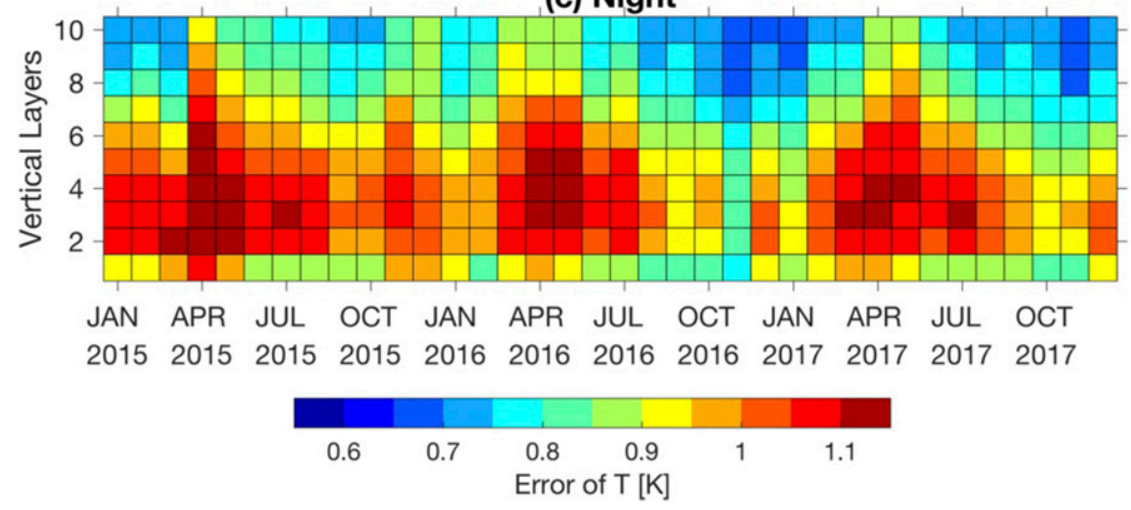

FIG. 11. The monthly DM forecast error of $T$ over the bottom-10 atmospheric model layers, corresponding to the sigma pressure levels between 0.82 and 1 (see section $2 \mathrm{a}$ ).

temperature/humidity and winds are very small, we can still see a relatively large absolute value of the error correlation over mountainous areas and Florida (e.g., Figs. 7e,k), which could be caused by thermally driven winds due to temperature differences such as sea breezes and mountain-valley circulations.

\section{b. Seasonal variability of the $\mathbf{B}$ matrix}

In this section, we demonstrate the seasonal variability of the $\mathbf{B}$ matrix by showing the results by month from 2015 to 2017 . We have investigated the spatial distribution of the error correlation between the soil moisture and atmospheric states in each month and found that the spatial pattern is generally very similar to that in the summer (see Figs. 6 and 7) but often with a smaller magnitude during the cold season (not shown). In addition, the spatial distribution of soil moisture forecast errors in different seasons has been extensively described and discussed in Lin et al. (2017b), showing that forecast errors are relatively large over the Great Plains in the summer but small over other areas and seasons when snow-covered areas are not considered. Therefore, for brevity, we present mainly the domain-mean values of the error statistics for each month.

Unlike the summer discussed in section 3a, the study domain during the cold season includes many areas that have frozen soils or are covered by snow. As we do not discuss error statistics over frozen soils, to find out where the frozen areas are, we show the spatial extent of the nonfrozen soil over the study domain in 2016, which is 
(a) All

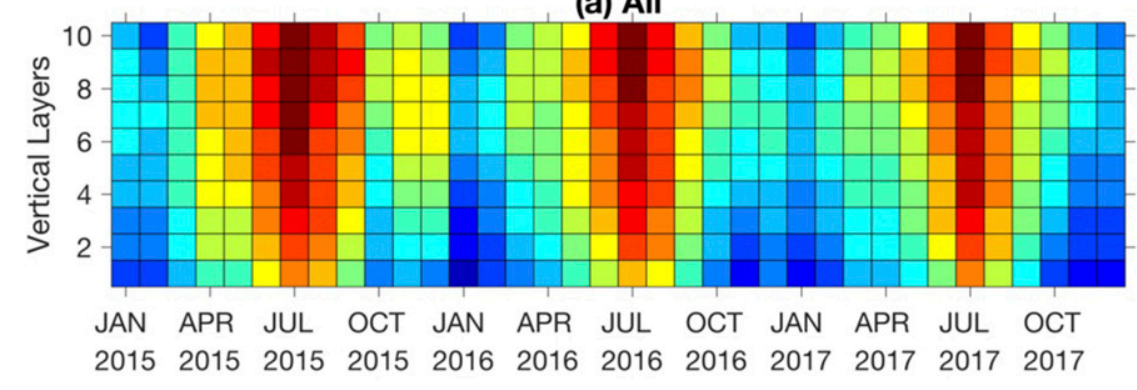

(b) Day

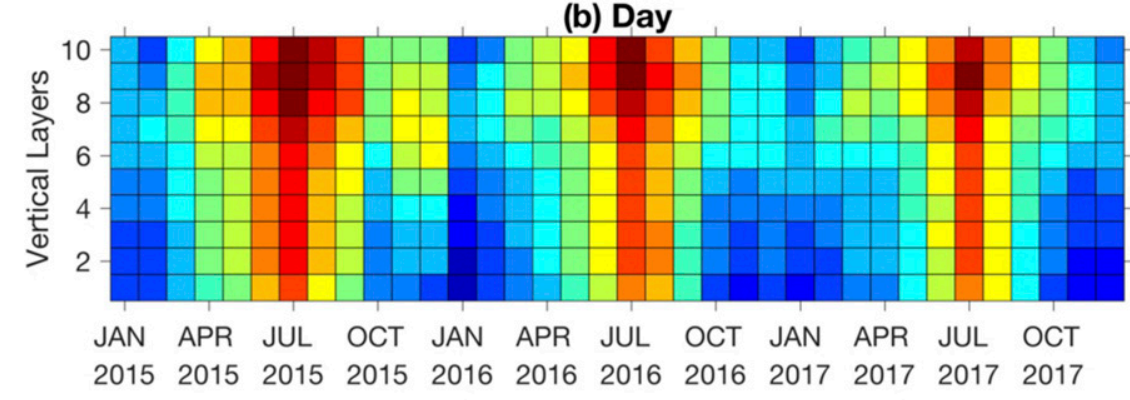

(c) Night

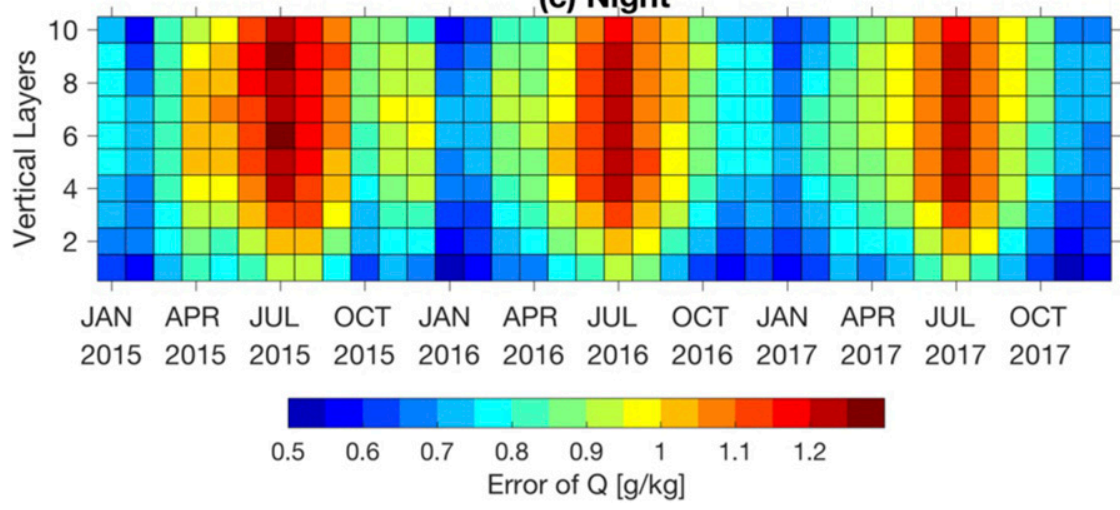

FIG. 12. As in Fig. 11, but for $Q$.

characterized by the simulated surface soil temperature (Fig. 8). The percentage of nonfrozen soils over land is also reported. Note that to maintain sufficient samples for computing the $\mathbf{B}$ matrix, we label a pixel as frozen soil with a very strict criterion, and the spatial extent of the frozen soils does not necessarily represent reality. It can be seen that during the cold season (e.g., from November to March), more than half of the land areas are cold or frozen. Together with the availability of SMAP retrieval data shown in Lin and Bras (2017), the results inform where and when assimilation of soil moisture is likely ineffective due to frozen conditions. The percentage of warm land pixels from 2015 to 2017 is shown in Fig. 9. Figure 9 shows that the temporal variability of frozen soil conditions is relatively stable and does not vary significantly annually. On the whole, assimilation of soil moisture is applicable over the contiguous United States mostly during the warm season (e.g., from May to October). Below, we compute the B matrix over only the warm land pixels.

Figure 10 shows the monthly variability of the domainmean error standard deviation $\sigma$ of the top-10-cm soil moisture over the warm land pixels from 2015 to 2017. The results show that the forecast error of soil moisture is largest during the summertime, which was also observed by Lin et al. (2017b). Although the variability varies slightly interannually, it can be seen that the domain-mean values are greater than $0.01 \mathrm{~m}^{3} \mathrm{~m}^{-3}$ from approximately May to October, during which time the daytime errors are often larger than the nighttime results. We note that the results in Fig. 10 are averaged over different geolocations as only warm pixels count. 
(a) All

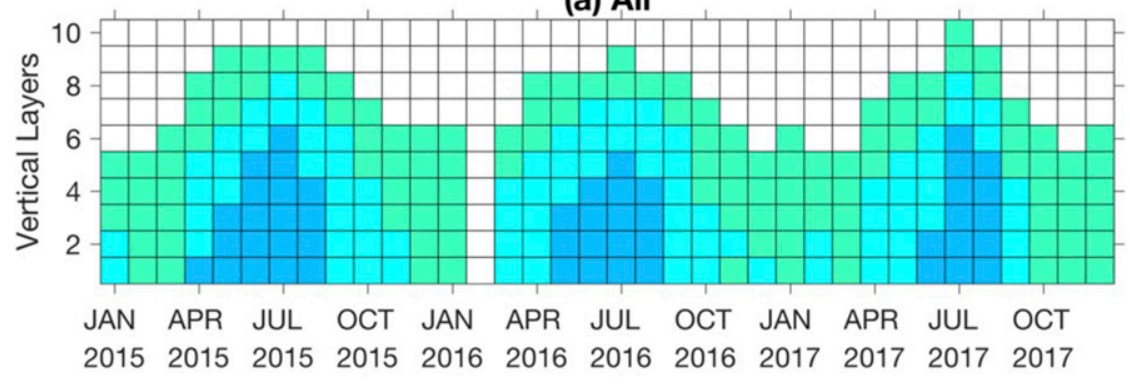

(b) Day

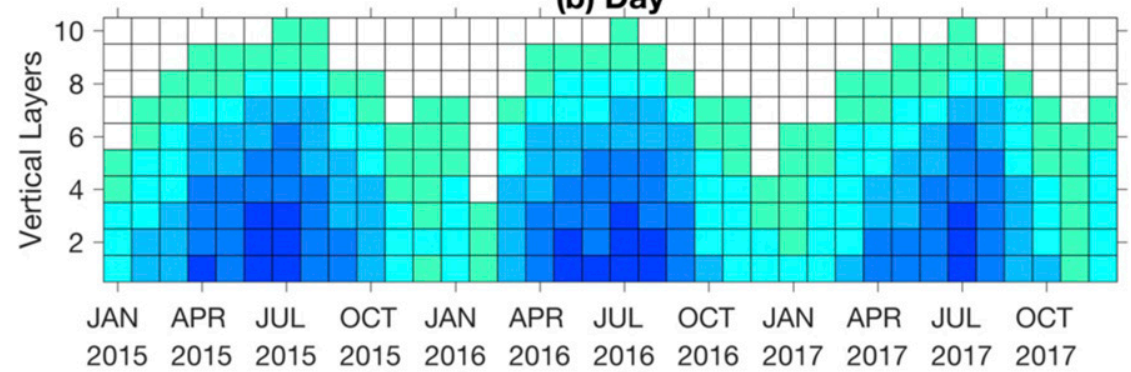

(c) Night

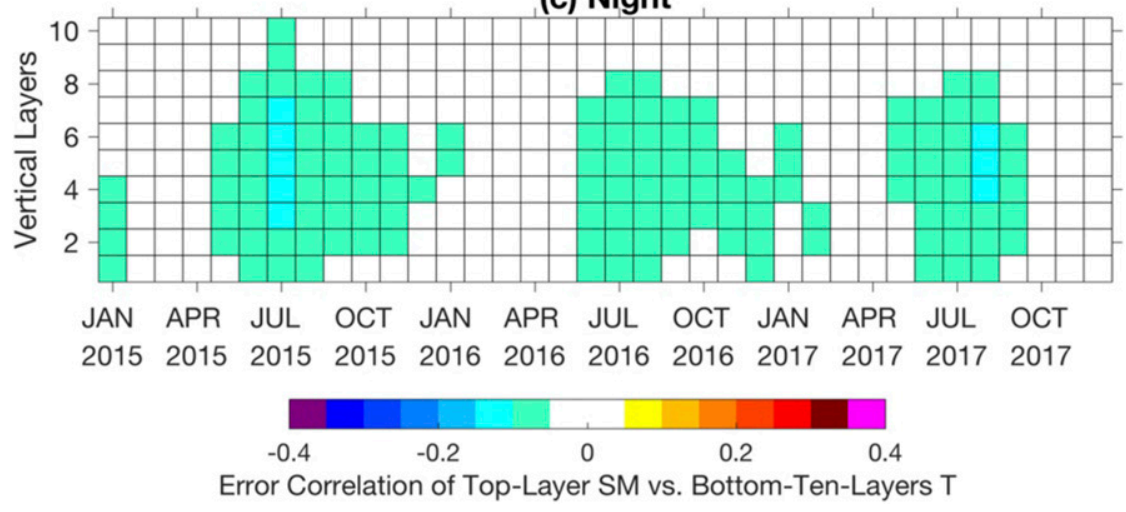

FIG. 13. The monthly DM values of the error correlation between the land surface SM and atmospheric $T$ over the bottom 10 layers, corresponding to the sigma pressure levels between 0.82 and 1 (see section 2a).

Nonetheless, we again computed the error standard deviation of the surface soil moisture for each month but over only warm pixels in January and found that the seasonal variability shown in Fig. 10 remains the same (not shown).

Figures 11 and 12 show the monthly domain-mean error standard deviation of atmospheric potential temperature and specific humidity in the bottom 10 layers over the warm land pixels. The corresponding sigma levels of each layer are described in section 2a. We report the results of temperature and humidity over only the bottom 10 layers, as our previous results indicate that a strong error correlation between soil moisture and atmospheric states is not seen at higher levels (Fig. 4).
For potential temperature, a large forecast error (i.e., greater than $1 \mathrm{~K}$ ) is often seen during the spring and summer over the bottom five layers (Fig. 11). For the specific humidity, Fig. 12 also shows that the large forecast errors (i.e., those greater than $1 \mathrm{~g} \mathrm{~kg}^{-1}$ ) are seen in the summer across the bottom 10 layers. In general, the results in Figs. 10-12 show that the forecast errors of both the soil moisture and atmospheric states (i.e., temperature and humidity) are relatively large during the warm seasons.

We further investigate the temporal variability of the error correlation in each month from 2015 to 2017. We examine the error correlation between the top-10-cm soil moisture and atmospheric states in Figs. 13 and 14 
(a) All

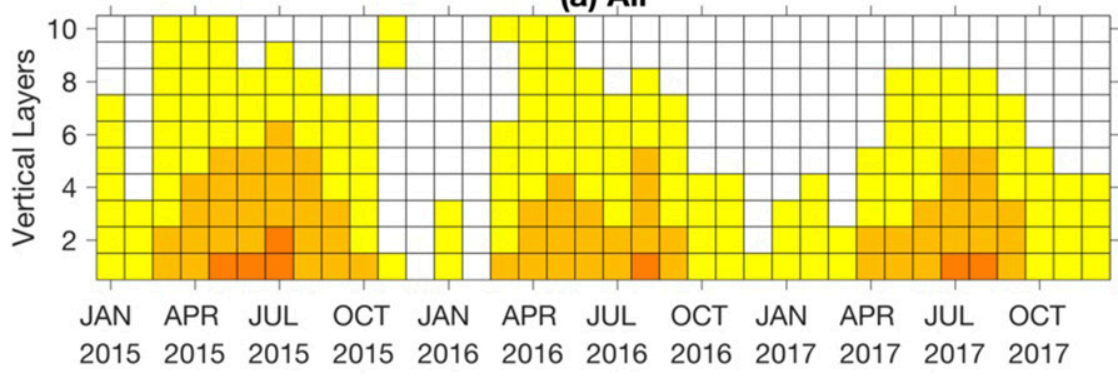

(b) Day

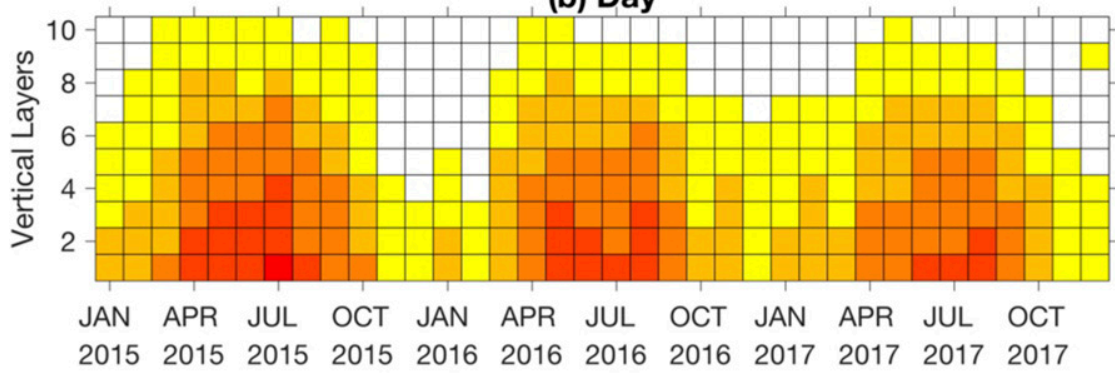

(c) Night

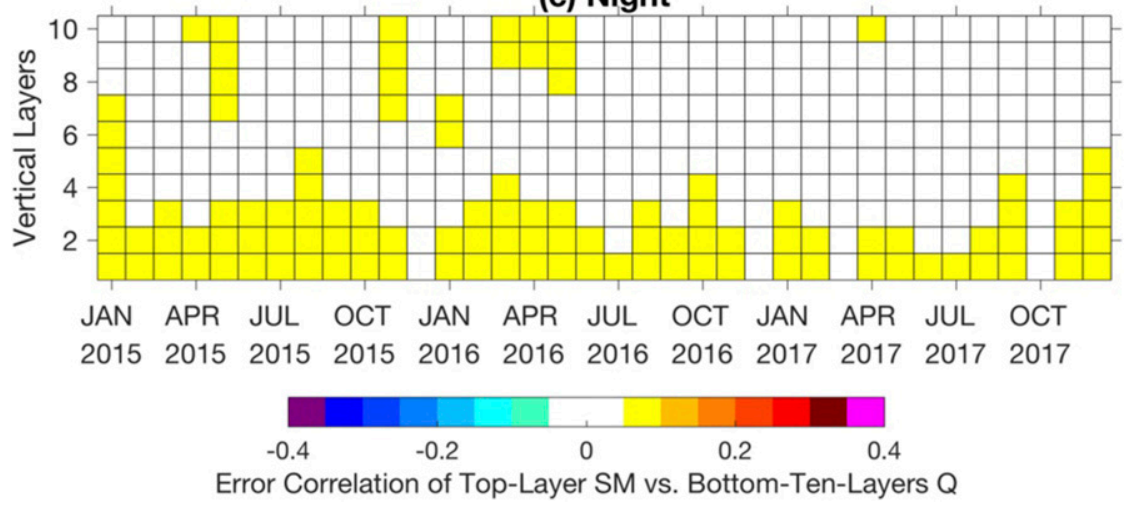

FIG. 14. As in Fig. 13, but for the land surface SM and $Q$ over the bottom-10 atmospheric layers.

and compare it with the error correlation between the bottom-layer potential temperature (specific humidity) and the specific humidity (potential temperature) over the bottom 10 layers shown in Fig. 15 (Fig. 16). The goal of the comparison is to see how much the forecast errors in a single layer at the near surface are linked to those of the temperature and humidity profiles. Figures $13 \mathrm{a}$ and 14a show that a large error correlation between surface soil moisture and temperature/humidity is often seen in the summer. During the summer, the magnitude of the absolute error correlation is greater than 0.15 for soil moisture versus temperature and is greater than 0.1 for soil moisture versus humidity over the bottom five layers, which suggests that assimilation of soil moisture data could impact not only the temperature and humidity near the surface but also those variables at higher levels. It is also found that such error correlation between soil moisture and temperature/humidity is seen mostly during the daytime.

Figures 15a and 16a show that a large error correlation with an absolute value of greater than 0.1 is often seen in the summer and sometimes in the winter. These all-time error correlations between atmospheric states are even smaller than those reported in Figs. 13 and 14. These small values of the all-time results are attributed to opposition in space and the difference between the daytime and nighttime error correlations. We can see that the error correlation between temperature and humidity is fairly strong during the daytime in the summer (Figs. 15b and 16b). However, such diurnal error variability is often not included in operational NWP variational systems. Overall, the results in this section 
(a) All

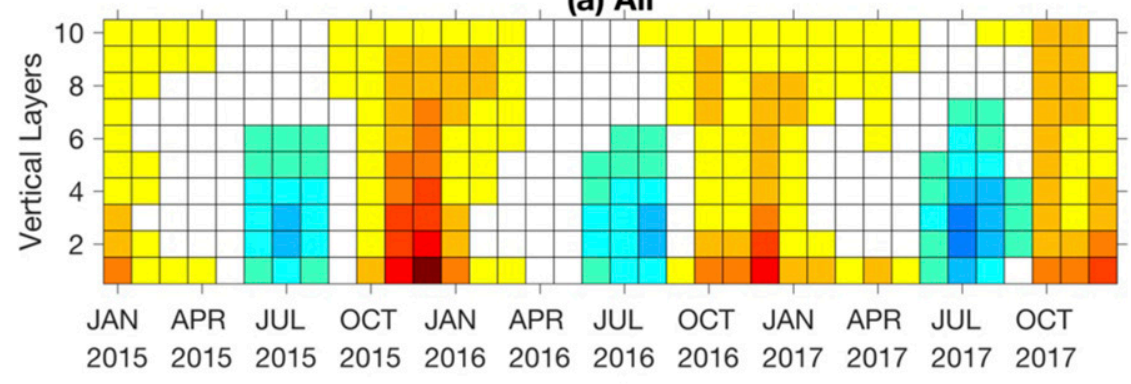

(b) Day

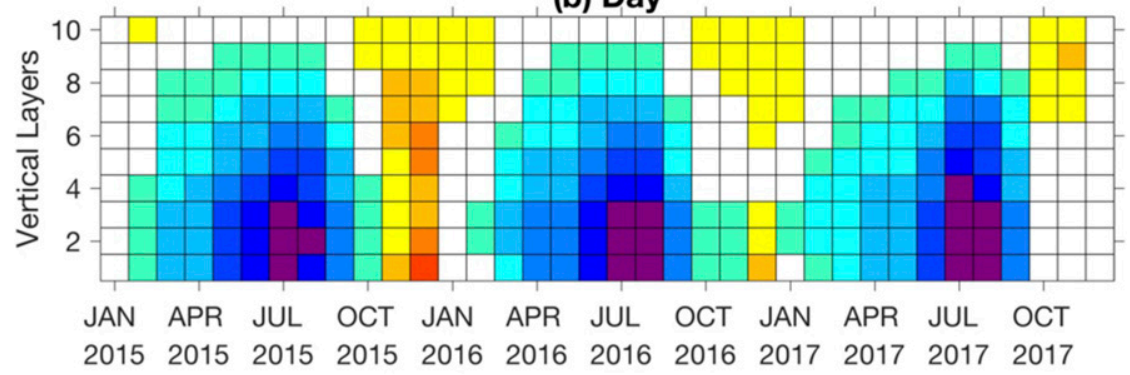

(c) Night

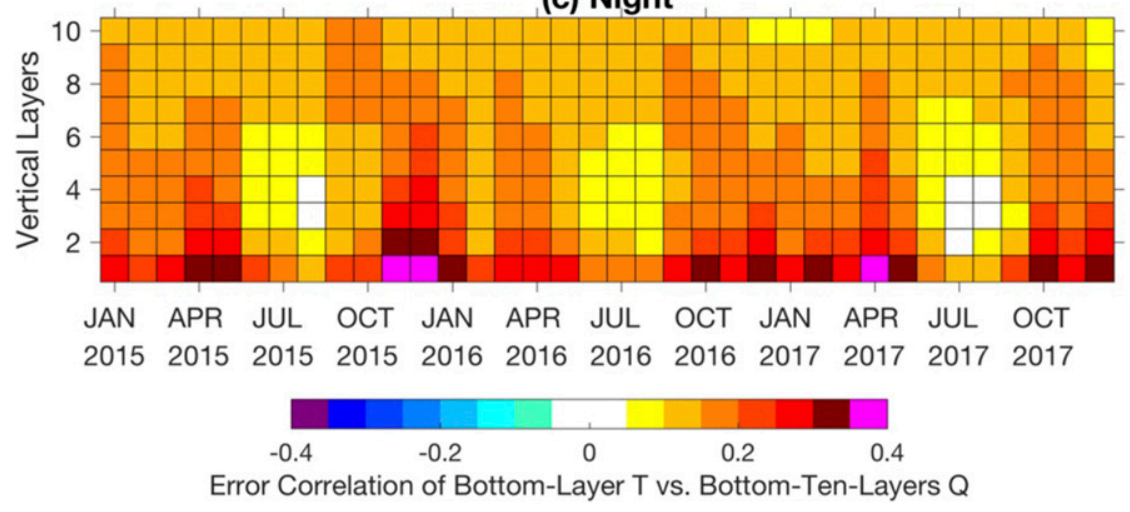

FIG. 15. As in Fig. 13, but for the bottom-layer $T$ and $Q$ over the bottom-10 atmospheric layers.

consistently demonstrate the potential of soil moisture data assimilation for atmospheric temperature and humidity states, particularly in the summer.

We also investigate the temporal variability of the domain-mean error correlation between surface soil moisture, bottom-layer potential temperature and specific humidity, and winds. For brevity, only the all-time results of single-layer soil moisture, temperature, and humidity versus the bottom-10-layer winds are shown (Fig. 17). Figure 17 shows on average a negligible error correlation value in the summer, which agrees well with Figs. 6 and 7. However, we observe a positive value of up to 0.2 for the error correlation between temperature/ humidity and winds during the cold season. The contrast could be attributed to the fact that in the summertime the wind errors over the lower atmosphere are mainly caused by random errors in a local-scale turbulence process (Hanna and Yang 2001), whereas in the winter, large-scale weather events such as fronts can lead to large forecast errors together in temperature, humidity, and winds.

\section{Concluding remarks}

In this study, we characterized the background error covariance between land surface soil moisture and atmospheric states, including potential temperature, specific humidity, and winds using the WRF-Noah Model in a strongly coupled system. In summary, we obtain the following key results:

- The background error covariance matrix shows strong temporal variability. The error standard deviations 
(a) All

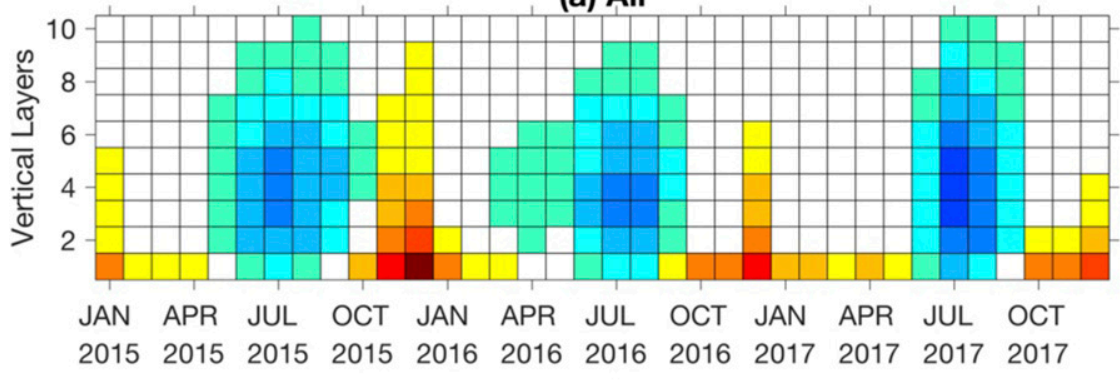

(b) Day

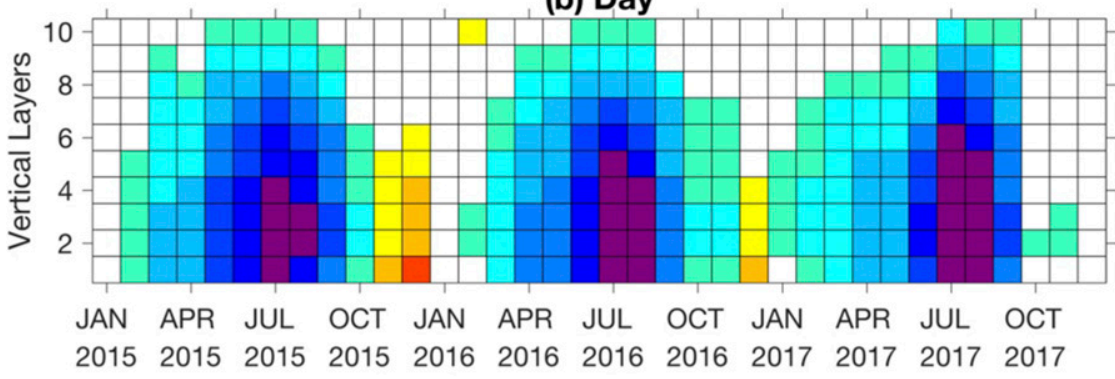

(c) Night

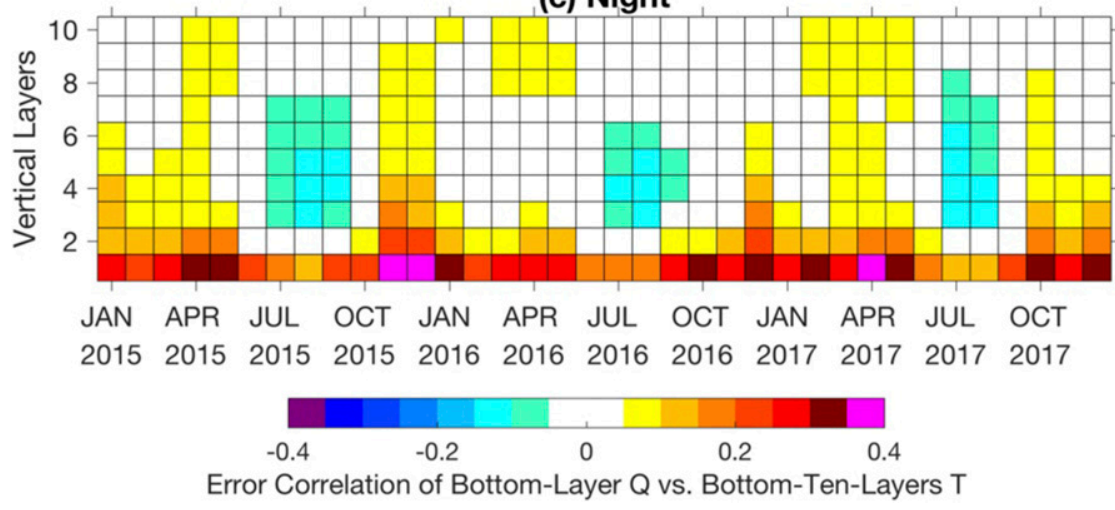

FIG. 16. As in Fig. 13, but for the bottom-layer $Q$ and $T$ over the bottom-10 atmospheric layers.

and correlations are relatively large during the warm season for soil moisture, temperature, and humidity. The monthly error correlation from all the forecast samples between soil moisture versus temperature/ humidity is comparable with that between temperature and humidity. Below a sigma pressure level of 0.9 during the summer, the absolute values of the error correlation between soil moisture and temperature/ humidity are as high as 0.15 .

- In terms of spatial variability, in the summer, large forecast errors of the top-layer soil moisture and bottom-layer temperature and humidity are often seen in approximately the Great Plains and Midwest. The error correlation between soil moisture and temperature/humidity is strong during the daytime over nearly the entire contiguous United States, while that between bottom-layer temperature and humidity shows a contrasting pattern in the West and East with diurnal variability. These spatial patterns are very similar during other seasons and at upper-air levels but show a smaller magnitude on average.

- The forecast errors of winds appear to be marginally correlated with those of surface soil moisture and atmospheric temperature and humidity in the summer.

Overall, the results demonstrate a strong connection between the forecast errors in land surface soil moisture and atmospheric temperature/humidity states and suggest that the assimilation of satellite soil moisture data (e.g., those from SMAP and SMOS) has a cross-variable impact similar to that of conventional near-surface temperature and humidity observations. The results imply 
(a) SM vs. U

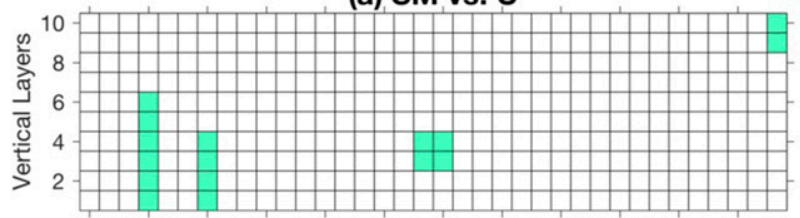

JAN APR JUL OCT JAN APR JUL OCT JAN APR JUL OCT 201520152015201520162016201620162017201720172017

(c) T vs. U

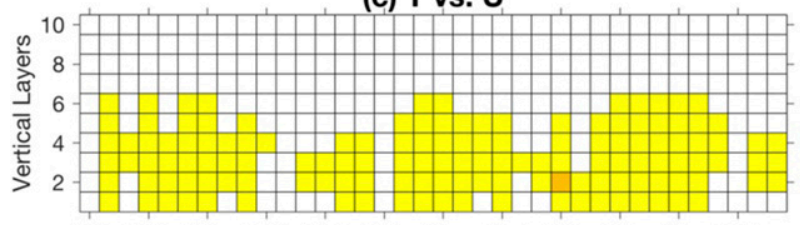

JAN APR JUL OCT JAN APR JUL OCT JAN APR JUL OCT 201520152015201520162016201620162017201720172017

(e) Q vs. U

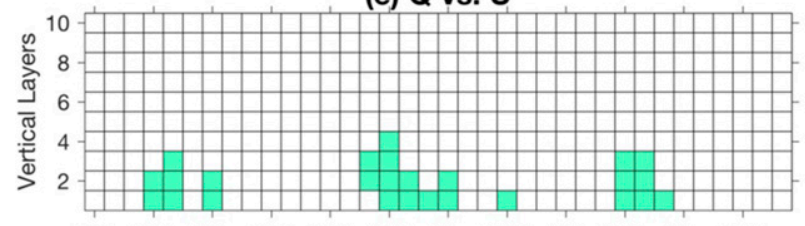

JAN APR JUL OCT JAN APR JUL OCT JAN APR JUL OCT 201520152015201520162016201620162017201720172017

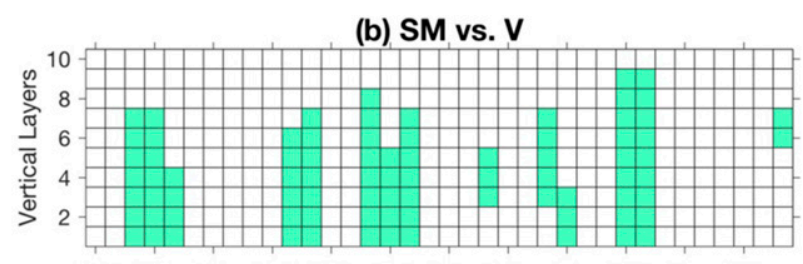

JAN APR JUL OCT JAN APR JUL OCT JAN APR JUL OCT 201520152015201520162016201620162017201720172017

(d) T vs. V

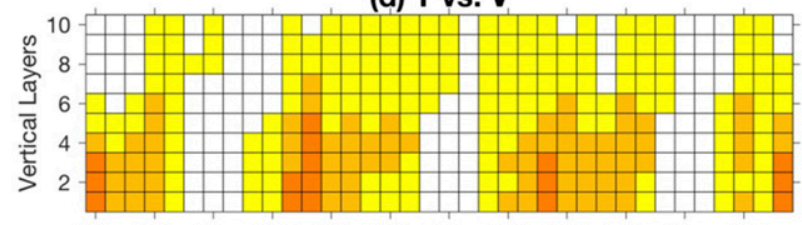

JAN APR JUL OCT JAN APR JUL OCT JAN APR JUL OCT 201520152015201520162016201620162017201720172017

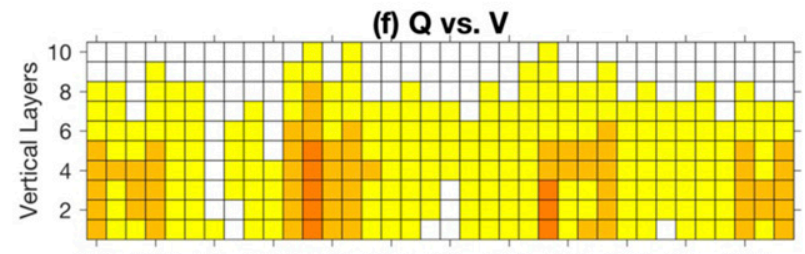

JAN APR JUL OCT JAN APR JUL OCT JAN APR JUL OCT 201520152015201520162016201620162017201720172017

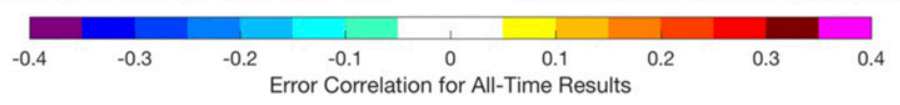

FIG. 17. The monthly DM values of the all-time error correlation between the top-layer SM and bottom-layer $T$ and $Q$ vs winds $(U$ and $V$ ) over the bottom-10 atmospheric layers.

that assimilation of satellite soil moisture data may be particularly helpful for predictions of low-troposphere temperature and humidity over areas without extensive coverage of surface observations (e.g., the Intermountain West and Africa). Nonetheless, we emphasize that the interpretation of the results reflects only the forecast errors of selected variables in a coupled land-atmosphere model. To demonstrate the direct impact of assimilating remotely sensed soil moisture data on NWP, one needs to include observations and their error characteristics. Future work can be devoted to the direct assimilation of satellite soil moisture data from SMAP/SMOS into a coupled land-atmosphere model under a framework of strongly coupled data assimilation.

Acknowledgments. This study is sponsored by NOAA/ NWS Award NA16NWS4680015. The support and resources from the Center for High Performance Computing at the University of Utah are gratefully acknowledged. We would also like to acknowledge high-performance computing at Cheyenne (doi:10.5065/D6RX99HX) provided by NCAR's Computational and Information Systems Laboratory, sponsored by the National Science Foundation. The NCEP FNL data were obtained from the
National Weather Service, which are freely available online [https://rda.ucar.edu/datasets/ds083.2/ $\left(1^{\circ}\right)$ and https://rda. ucar.edu/datasets/ds083.3/ $\left.\left(0.25^{\circ}\right)\right]$. The WRF Model was obtained from NCAR and is freely available online (http:// www2.mmm.ucar.edu/wrf/users/). We thank these agencies for providing the model, data, and technical assistance. The authors also thank three anonymous reviewers for their helpful comments.

\section{REFERENCES}

Aligo, E. A., W. A. Gallus, and M. Segal, 2007: Summer rainfall forecast spread in an ensemble initialized with different soil moisture analyses. Wea. Forecasting, 22, 299-314, https://doi.org/ 10.1175/WAF995.1.

Bannister, R. N., 2008a: A review of forecast error covariance statistics in atmospheric variational data assimilation. I: Characteristics and measurements of forecast error covariances. Quart. J. Roy. Meteor. Soc., 134, 1951-1970, https:// doi.org/10.1002/qj.339.

_ 2008b: A review of forecast error covariance statistics in atmospheric variational data assimilation. II: Modelling the forecast error covariance statistics. Quart. J. Roy. Meteor. Soc., 134, 1971-1996, https://doi.org/10.1002/qj.340.

Barker, D., W. Huang, Y.-R. Guo, A. J. Bourgeois, and N. Xiao, 2004: A three-dimensional variational data assimilation system 
for MM5: Implementation and initial results. Mon. Wea. Rev., 132, 897-914, https://doi.org/10.1175/1520-0493(2004)132<0897: ATVDAS $>2.0 . \mathrm{CO} ; 2$.

— and Coauthors, 2012: The Weather Research and Forecasting (WRF) Model's Community Variational/Ensemble Data Assimilation System: WRFDA. Bull. Amer. Meteor. Soc., 93, 831-843, https://doi.org/10.1175/BAMS-D-11-00167.1.

Bélair, S., L.-P. Crevier, J. Mailhot, B. Bilodeau, and Y. Delage, 2003: Operational implementation of the ISBA land surface scheme in the Canadian regional weather forecast model. Part I: Warm season results. J. Hydrometeor., 4, 352-370, https:// doi.org/10.1175/1525-7541(2003)4<352:OIOTIL >2.0.CO;2.

Blankenship, C. B., J. L. Case, B. T. Zavodsky, and W. L. Crosson, 2016: Assimilation of SMOS retrievals in the Land Information System. IEEE Trans. Geosci. Remote Sens., 54, 6320-6332, https://doi.org/10.1109/TGRS.2016.2579604.

Case, J. L., W. L. Crosson, S. V. Kumar, W. M. Lapenta, and C. D. Peters-Lidard, 2008: Impacts of high-resolution land surface initialization on regional sensible weather forecasts from the WRF Model. J. Hydrometeor., 9, 1249-1266, https://doi.org/ 10.1175/2008JHM990.1.

_ , S. V. Kumar, J. Srikishen, and G. J. Jedlovec, 2011: Improving numerical weather predictions of summertime precipitation over the southeastern United States through a high-resolution initialization of the surface state. Wea. Forecasting, 26, 785807, https://doi.org/10.1175/2011WAF2222455.1.

Chen, F., and J. Dudhia, 2001: Coupling an advanced land surfacehydrology model with the Penn State-NCAR MM5 modeling system. Part I: Model implementation and sensitivity. Mon. Wea. Rev., 129, 569-585, https://doi.org/10.1175/1520-0493(2001) $129<0569$ :CAALSH $>2.0 . \mathrm{CO} ; 2$

Choi, Y., D.-H. Cha, M.-I. Lee, J. Kim, C.-S. Jin, S.-H. Park, and M.-S. Joh, 2017: Satellite radiance data assimilation for binary tropical cyclone cases over the western North Pacific. J. Adv. Model. Earth Syst., 9, 832-853, https://doi.org/10.1002/2016MS000826.

Courtier, P., and Coauthors, 1998: The ECMWF implementation of three-dimensional variational assimilation (3D-Var). I: Formulation. Quart. J. Roy. Meteor. Soc., 124, 1783-1807, https://doi.org/10.1002/qj.49712455002.

Dee, D. P., and Coauthors, 2011: The ERA-Interim reanalysis: Configuration and performance of the data assimilation system. Quart. J. Roy. Meteor. Soc., 137, 553-597, https://doi.org/ 10.1002/qj.828.

De Rosnay, P., M. Drusch, D. Vasiljevic, G. Balsamo, C. Albergel, and L. Isaksen, 2013: A simplified extended Kalman filter for the global operational soil moisture analysis at ECMWF. Quart. J. Roy. Meteor. Soc., 139, 1199-1213, https://doi.org/ 10.1002/qj.2023.

— , G. Balsamo, C. Albergel, J. Munoz-Sabater, and L. Isaksen, 2014: Initialisation of land surface variables for numerical weather prediction. Surv. Geophys., 35, 607-621, https:// doi.org/10.1007/s10712-012-9207-x.

Douville, H., P. Viterbo, J.-F. Mahfouf, and A. C. M. Beljaars, 2000: Evaluation of the optimum interpolation and nudging techniques for soil moisture analysis using FIFE data. Mon. Wea. Rev., 128, 1733-1756, https://doi.org/10.1175/ 1520-0493(2000)128<1733:EOTOIA > 2.0.CO;2.

Draper, C. S., J.-F. Mahfouf, and J. P. Walker, 2009: An EKF assimilation of AMSR-E soil moisture into the ISBA land surface scheme. J. Geophys. Res., 114, D20104, https://doi.org/ 10.1029/2008JD011650.

,$- \ldots$, and ——, 2011: Root zone soil moisture from the assimilation of screen-level variables and remotely sensed soil moisture. J. Geophys. Res., 116, D02127, https://doi.org/ 10.1029/2010JD013829.

—, R. H. Reichle, G. J. M. D. Lannoy, and Q. Liu, 2012: Assimilation of passive and active microwave soil moisture retrievals. Geophys. Res. Lett., 39, L04401, https://doi.org/10.1029/2011GL050655.

Drusch, M., K. Scipal, P. de Rosnay, G. Balsamo, E. Andersson, P. Bougeault, and P. Viterbo, 2009: Towards a Kalman filter based soil moisture analysis system for the operational ECMWF Integrated Forecast System. Geophys. Res. Lett., 36, L10401, https://doi.org/10.1029/2009GL037716.

Duerinckx, A., R. Hamdi, A. Deckmyn, A. Djebbar, J.-F. Mahfouf, and P. Termonia, 2017: Combining an EKF soil analysis with a 3DVar upper-air assimilation in a limited-area NWP model. Quart. J. Roy. Meteor. Soc., 143, 2999-3013, https://doi.org/10.1002/qj.3141.

Entekhabi, D., and Coauthors, 2010: The Soil Moisture Active Passive (SMAP) mission. Proc. IEEE, 98, 704-716, https:// doi.org/10.1109/JPROC.2010.2043918.

Giard, D., and E. Bazile, 2000: Implementation of a new assimilation scheme for soil and surface variables in a global NWP model. Mon. Wea. Rev., 128, 997-1015, https://doi.org/10.1175/ 1520-0493(2000)128<0997:IOANAS > 2.0.CO;2.

Hanna, S. R., and R. Yang, 2001: Evaluations of mesoscale models' simulations of near-surface winds, temperature gradients, and mixing depths. J. Appl. Meteor., 40, 1095-1104, https://doi.org/ 10.1175/1520-0450(2001)040<1095:EOMMSO>2.0.CO;2.

Hohenegger, C., P. Brockhaus, C. S. Bretherton, and C. Schar, 2009: The soil moisture-precipitation feedback in simulations with explicit and parameterized convection. J. Climate, 22, 5003-5020, https://doi.org/10.1175/2009JCLI2604.1.

Iacono, M. J., J. S. Delamere, E. J. Mlawer, M. W. Shephard, S. A. Clough, and W. D. Collins, 2008: Radiative forcing by longlived greenhouse gases: Calculations with the AER radiative transfer models. J. Geophys. Res., 113, D13103, https://doi.org/ 10.1029/2008JD009944.

Ide, K., P. Courtier, M. Ghil, and A. C. Lorenc, 1997: Unified notation for data assimilation: Operational, sequential, and variational. J. Meteor. Soc. Japan, 75, 181-189, https://doi.org/ 10.2151/jmsj1965.75.1B_181.

Ingleby, N. B., 2001: The statistical structure of forecast errors and its representation in the Met Office global 3-D variational data assimilation scheme. Quart.J. Roy. Meteor. Soc., 127, 209-231, https://doi.org/10.1002/qj.49712757112.

Janjić, Z. I., 1994: The step-mountain eta coordinate model: Further developments of the convection, viscous sublayer, and turbulence closure schemes. Mon. Wea. Rev., 122, 927-945, https://doi.org/ 10.1175/1520-0493(1994)122<0927:TSMECM > 2.0.CO;2.

_ 2002: Nonsingular implementation of the Mellor-Yamada level 2.5 scheme in the NCEP meso model. NCEP Office Note 437, 61 pp., https://www.emc.ncep.noaa.gov/officenotes/ newernotes/on437.pdf.

Kerr, Y.H., and Coauthors, 2010: The SMOS mission: New tool from monitoring key elements of the global water cycle. Proc. IEEE, 98, 666-687, https://doi.org/10.1109/JPROC.2010.2043032.

Kolassa, J., R. H. Reichle, and C. S. Draper, 2017: Merging active and passive microwave observations in soil moisture data assimilation. Remote Sens. Environ., 191, 117-130, https:// doi.org/10.1016/j.rse.2017.01.015.

Koster, R. D., and Coauthors, 2004: Regions of strong coupling between soil moisture and precipitation. Science, 305, 11381140, https://doi.org/10.1126/science.1100217.

, and Coauthors, 2006: GLACE: The Global Land-Atmosphere Coupling Experiment. Part I: Overview. J. Hydrometeor., 7, 590-610, https://doi.org/10.1175/JHM510.1. 
Kumar, S. V., R. H. Reichle, C. D. Peters-Lidard, R. D. Koster, X. Zhan, W. T. Crow, J. B. Eylander, and P. R. Houser, 2008: A land surface data assimilation framework using the land information system: Description and applications. Adv. Water Resour., 31, 1419-1432, https://doi.org/10.1016/ j.advwatres.2008.01.013.

— , and Coauthors, 2014: Assimilation of remotely sensed soil moisture and snow depth retrievals for drought estimation. J. Hydrometeor., 15, 2446-2469, https://doi.org/10.1175/JHMD-13-0132.1.

— C. D. Peters-Lidard, J. A. Santanello, R. H. Reichle, C. S. Draper, R. D. Koster, G. Nearing, and M. F. Jasinski, 2015: Evaluating the utility of satellite soil moisture retrievals over irrigated areas and the ability of land data assimilation methods to correct for unmodeled processes. Hydrol. Earth Syst. Sci., 19, 4463-4478, https://doi.org/10.5194/hess-19-44632015.

Li, Z., Z. Pu, J. Sun, and W.-C. Lee, 2014: Impact of 4DVAR assimilation of airborne Doppler radar observations on numerical simulations of the genesis of Typhoon Nuri (2008). J. Appl. Meteor. Climatol., 53, 2325-2343, https://doi.org/10.1175/ JAMC-D-14-0046.1.

Lin, L.-F., and R. L. Bras, 2017: Monthly maps of SMAP L2 version 4 soil moisture retrievals over contiguous United States in 2016: Data sample size under various quality flags. School of Civil and Environmental Engineering Publ., Georgia Institute of Technology, 13 pp., http://hdl.handle.net/1853/56688.

, A. M. Ebtehaj, R. L. Bras, A. N. Flores, and J. Wang, 2015: Dynamical precipitation downscaling for hydrologic applications using WRF 4D-Var data assimilation: Implications for GPM era. J. Hydrometeor., 16, 811-829, https://doi.org/ 10.1175/JHM-D-14-0042.1.

,,-- A. N. Flores, S. Bastola, and R. L. Bras, 2017a: Combined assimilation of satellite precipitation and soil moisture: A case study using TRMM and SMOS data. Mon. Wea. Rev., 145, 4997-5014, https://doi.org/10.1175/MWR-D-17-0125.1.

,,-- J. Wang, and R. L. Bras, 2017b: Soil moisture background error covariance and data assimilation in a coupled land-atmosphere model. Water Resour. Res., 53, 1309-1335, https://doi.org/10.1002/2015WR017548.

Lorenc, A. C., and Coauthors, 2000: The Met. Office global threedimensional variational data assimilation scheme. Quart. J. Roy. Meteor. Soc., 126, 2991-3012, https://doi.org/10.1002/ qj. 49712657002.

Mahfouf, J.-F., 1991: Analysis of soil moisture from near-surface parameters: A feasibility study. J. Appl. Meteor., 30, 1534-1547, https://doi.org/10.1175/1520-0450(1991)030<1534: AOSMFN $>2.0 . \mathrm{CO} ; 2$.

_ 2010: Assimilation of satellite-derived soil moisture from ASCAT in a limited-area NWP model. Quart. J. Roy. Meteor. Soc., 136, 784-798, https://doi.org/10.1002/qj.602.

_ observations and radar-derived precipitation for soil moisture analysis. Quart. J. Roy. Meteor. Soc., 137, 709-722, https://doi.org/ 10.1002/qj.791.

—, K. Bergaoui, C. Draper, F. Bouyssel, F. Taillefer, and L. Taseva, 2009: A comparison of two off-line soil analysis schemes for assimilation of screen level observations. J. Geophys. Res., 114, D08105, https://doi.org/10.1029/ 2008JD011077.

Massey, J. D., W. J. Steenburgh, J. C. Knievel, and W. Y. Y. Cheng, 2016: Regional soil moisture biases and their influence on WRF Model temperature forecasts over the Intermountain
West. Wea. Forecasting, 31, 197-216, https://doi.org/10.1175/ WAF-D-15-0073.1.

Meng, Z., and F. Zhang, 2007: Tests of an ensemble Kalman filter for mesoscale and regional-scale data assimilation. Part II: Imperfect model experiments. Mon. Wea. Rev., 135, 14031423, https://doi.org/10.1175/MWR3352.1.

$\longrightarrow$, and — 2008: Tests of an ensemble Kalman filter for mesoscale and regional-scale data assimilation. Part III: Comparison with 3DVAR in a real-data case study. Mon. Wea. Rev., 136, 522-540, https://doi.org/10.1175/2007MWR2106.1.

NWS, 2000: NCEP FNL operational model global tropospheric analyses, continuing from July 1999 (updated daily). National Center for Atmospheric Research Computational and Information Systems Laboratory Research Data Archive, accessed 3 January 2018, https://doi.org/10.5065/D6M043C6.

_ 2015 : NCEP GDAS/FNL 0.25 degree global tropospheric analyses and forecast grids. National Center for Atmospheric Research Computational and Information Systems Laboratory Research Data Archive, accessed 3 January 2018, https:// doi.org/10.5065/D65Q4T4Z.

Parrens, M., J.-F. Mahfouf, A. L. Barbu, and J.-C. Calvet, 2014: Assimilation of surface soil moisture into a multilayer soil model: Design and evaluation at local scale. Hydrol. Earth Syst. Sci., 18, 673-689, https://doi.org/10.5194/hess-18-673-2014.

Parrish, D. F., and J. C. Derber, 1992: The National Meteorological Center's spectral statistical-interpolation analysis system. Mon. Wea. Rev., 120, 1747-1763, https://doi.org/10.1175/15200493(1992)120<1747:TNMCSS $>2.0$. CO;2.

Penny, S. G., and T. M. Hamill, 2017: Coupled data assimilation for integrated Earth system analysis and prediction. Bull. Amer. Meteor. Soc., 98, ES169-ES172, https://doi.org/10.1175/ BAMS-D-17-0036.1.

— , and Coauthors, 2017: Coupled data assimilation for integrated earth system analysis and prediction: Goals, challenges and recommendations. World Weather Research Programme Rep. WWRP 2017-3, 50 pp., https://www.wmo.int/pages/prog/arep/ wwrp/new/documents/Final_WWRP_2017_3_27_July.pdf.

Powers, J. G., and Coauthors, 2017: The Weather Research and Forecasting Model. Bull. Amer. Meteor. Soc., 98, 1717-1737, https://doi.org/10.1175/BAMS-D-15-00308.1.

$\mathrm{Pu}, \mathrm{Z}$., 2017: Surface data assimilation and near-surface weather prediction over complex terrain. Data Assimilation for Atmospheric, Oceanic and Hydrologic Applications, Vol. III, S. K. Park and L. Xu, Eds., Springer, 219-240, https:/doi.org/ 10.1007/978-3-319-43415-5_10.

Quintanar, A. I., and R. Mahmood, 2012: Ensemble forecast spread induced by soil moisture changes over mid-south and neighboring mid-western region of the USA. Tellus, $\mathbf{6 4 A}$, 17156, https://doi.org/10.3402/tellusa.v64i0.17156.

Rasmy, M., T. Koike, S. Boussetta, H. Lu, and X. Li, 2011: Development of a satellite land data assimilation system coupled with a mesoscale model in the Tibetan Plateau. IEEE Trans. Geosci. Remote Sens., 49, 2847-2862, https://doi.org/10.1109/ TGRS.2011.2112667.

,-- - D. Kuria, C. R. Mirza, X. Li, and K. Yang, 2012: Development of the Coupled Atmosphere and Land Data Assimilation System (CALDAS) and its application over the Tibetan Plateau. IEEE Trans. Geosci. Remote Sens., 50, 42274242, https://doi.org/10.1109/TGRS.2012.2190517.

Reichle, R. H., and R. D. Koster, 2005: Global assimilation of satellite surface soil moisture retrievals into the NASA Catchment land surface model. Geophys. Res. Lett., 32, L02404, https://doi.org/10.1029/2004GL021700. 
,-- , P. Liu, S. P. P. Mahanama, E. G. Njoku, and M. Owe, 2007: Comparison and assimilation of global soil moisture retrievals from the Advanced Microwave Scanning Radiometer for the Earth Observing System (AMSR-E) and the Scanning Multichannel Microwave Radiometer (SMMR). J. Geophys. Res., 112, D09108, https://doi.org/10.1029/2006JD008033.

— - W. T. Crow, and C. L. Keppenne, 2008: An adaptive ensemble Kalman filter for soil moisture data assimilation. Water Resour. Res., 44, W03423, https://doi.org/10.1029/ 2007WR006357.

Sahoo, A. K., G. J. M. De Lannoy, R. H. Reichle, and P. R. Houser, 2013: Assimilation and downscaling of satellite observed soil moisture over the Little River experimental watershed in Georgia, USA. Adv. Water Resour., 52, 19-33, https://doi.org/ 10.1016/j.advwatres.2012.08.007.

Santanello, J. A., S. V. Kumar, C. D. Peters-Lidard, and P. M. Lawston, 2016: Impact of soil moisture assimilation on land surface model spinup and coupled land-atmosphere prediction. J. Hydrometeor., 17, 517-540, https://doi.org/10.1175/ JHM-D-15-0072.1.

Schneider, S., Y. Wang, W. Wanger, and J.-F. Mahfouf, 2014: Impact of ASCAT soil moisture assimilation on regional precipitation forecasts: A case study for Austria. Mon. Wea. Rev., 142, 1525-1541, https://doi.org/10.1175/MWR-D-12-00311.1.

Seto, R., T. Koike, and M. Rasmy, 2016: Heavy rainfall prediction applying satellite-based cloud data assimilation over land J. Geophys. Res. Atmos., 121, 9737-9755, https://doi.org/ 10.1002/2016JD025291.

Shao, H., and Coauthors, 2016: Bridging research to operations transitions: Status and plans of community GSI. Bull. Amer. Meteor. Soc., 97, 1427-1440, https://doi.org/10.1175/BAMS-D13-00245.1.

Skamarock, W. C., and Coauthors, 2008: A description of the Advanced Research WRF version 3. NCAR Tech. Note NCAR/TN-475+STR, 113 pp., http://dx.doi.org/10.5065/ D68S4MVH

Sun, J., H. Wang, W. Tong, Y. Zhang, C.-Y. Lin, and D. Xu, 2016: Comparison of the impacts of momentum control variables on high-resolution variational data assimilation and precipitation forecasting. Mon. Wea. Rev., 144, 149-169, https://doi.org/ 10.1175/MWR-D-14-00205.1.

Sutton, C., T. M. Hamill, and T. T. Warner, 2006: Will perturbing soil moisture improve warm-season ensemble forecasts? A proof of concept. Mon. Wea. Rev., 134, 3174-3189, https://doi.org/ 10.1175/MWR3248.1.

Thompson, G., P. R. Field, R. M. Rasmussen, and W. D. Hall, 2008: Explicit forecasts of winter precipitation using an improved bulk microphysics scheme. Part II: Implementation of a new snow parameterization. Mon. Wea. Rev., 136, 5095-5115, https://doi.org/10.1175/2008MWR2387.1.

Tiedtke, M., 1989: A comprehensive mass flux scheme for cumulus parameterization in large-scale models. Mon. Wea. Rev., 117, 1779-1800, https://doi.org/10.1175/1520-0493(1989)117<1779: $\mathrm{ACMFSF}>2.0 . \mathrm{CO} ; 2$.

Trier, S. B., F. Chen, K. W. Manning, M. A. LeMone, and C. A. Davis, 2008: Sensitivity of the PBL and precipitation in 12-day simulations of warm-season convection using different land surface models and soil wetness conditions. Mon. Wea. Rev., 136, 2321-2343, https://doi.org/10.1175/2007MWR2289.1.
Tuttle, S., and G. Salvucci, 2016: Empirical evidence of contrasting soil moisture-precipitation feedbacks across the United States. Science, 352, 825-828, https://doi.org/10.1126/science. aaa7185.

Uppala, S. M., and Coauthors, 2005: The ERA-40 Re-Analysis. Quart. J. Roy. Meteor. Soc., 131, 2961-3012, https://doi.org/ 10.1256/qj.04.176.

Van Weverberg, K. V., N. P. M. van Lipzig, L. Delobbe, and D. Lauwaet, 2010: Sensitivity of quantitative precipitation forecast to soil moisture initialization and microphysics parameterization. Quart. J. Roy. Meteor. Soc., 136, 978-996, https://doi.org/10.1002/qj.611.

Wang, H., X.-Y. Huang, J. Sun, D. Xu, M. Zhang, S. Fan, and J. Zhong, 2014: Inhomogeneous background error modeling for WRF-Var using the NMC method. J. Appl. Meteor. Climatol., 53, 2287-2309, https://doi.org/10.1175/JAMC-D-130281.1

Wu, C.-C., G.-Y. Lien, J.-H. Chen, and F. Zhang, 2010: Assimilation of tropical cyclone track and structure based on the ensemble Kalman filter (EnKF). J. Atmos. Sci., 67, 3806-3822, https://doi.org/10.1175/2010JAS3444.1.

Wu, W.-S., R. J. Purser, and D. F. Parrish, 2002: Three-dimensional variational analysis with spatially inhomogeneous covariances. Mon. Wea. Rev., 130, 2905-2916, https://doi.org/ 10.1175/1520-0493(2002)130<2905:TDVAWS > 2.0.CO;2

Xu, X., B. A. Tolson, J. Li, R. M. Staebler, F. Seglenieks, A. Haghnegahdar, and B. Davison, 2015: Assimilation of SMOS soil moisture over the Great Lakes basin. Remote Sens. Environ., 169, 163-175, https://doi.org/10.1016/ j.rse.2015.08.017.

,,--- , and B. Davison, 2017: Comparison of X-band and L-band soil moisture retrievals for land data assimilation. IEEE J. Sel. Top. Appl. Earth Obs. Remote Sens., 10, 38503860, https://doi.org/10.1109/JSTARS.2017.2703988.

Yang, C., Z. Liu, J. Bresch, S. R. H. Rizvi, X.-Y. Huang, and J. Min, 2016: AMSR2 all-sky radiance assimilation and its impact on the analysis and forecast of Hurricane Sandy with a limitedarea data assimilation system. Tellus, $\mathbf{6 8}, 30917$, https://doi.org/ 10.3402/tellusa.v68.30917

Yin, J., X. Zhan, Y. Zheng, J. Liu, C. R. Hain, and L. Fang, 2014: Impact of quality control of satellite soil moisture data on their assimilation into land surface model. Geophys. Res. Lett., 41, 7159-7166, https://doi.org/10.1002/2014GL060659.

,-- J. Liu, L. Fang, and C. R. Hain, 2015: Enhancing model skill by assimilating SMOPS-blended soil moisture product into Noah land surface model. J. Hydrometeor., 16, 917-931, https://doi.org/10.1175/JHM-D-14-0070.1.

Zhang, C., Y. Wang, and K. Hamilton, 2011: Improved representation of boundary layer clouds over the southeast Pacific in ARW-WRF using a modified Tiedtke cumulus parameterization scheme. Mon. Wea. Rev., 139, 3489-3513, https://doi.org/ 10.1175/MWR-D-10-05091.1.

Zhang, F., Z. Meng, and A. Aksoy, 2006: Tests of an ensemble Kalman filter for mesoscale and regional-scale data assimilation. Part I: Perfect model experiments. Mon. Wea. Rev., 134, 722-736, https://doi.org/10.1175/MWR3101.1.

Zhang, H., Z. Pu, and X. Zhang, 2013: Examination of errors in near-surface temperature and wind from WRF numerical simulations in regions of complex terrain. Wea. Forecasting, 28, 893-914, https://doi.org/10.1175/WAF-D-12-00109.1. 